\title{
From Geocentrism to Allocentrism: Teaching the Phases of the Moon in a Digital Full-Dome Planetarium
}

\author{
Pierre Chastenay
}

Published online: 7 February 2015

(C) The Author(s) 2015. This article is published with open access at Springerlink.com

\begin{abstract}
An increasing number of planetariums worldwide are turning digital, using ultrafast computers, powerful graphic cards, and high-resolution video projectors to create highly realistic astronomical imagery in real time. This modern technology makes it so that the audience can observe astronomical phenomena from a geocentric as well as an allocentric perspective (the view from space). While the dome creates a sense of immersion, the digital planetarium introduces a new way to teach astronomy, especially for topics that are inherently three-dimensional and where seeing the phenomenon from different points of view is essential. Like a virtual-reality environment, an immersive digital planetarium helps learners create a more scientifically accurate visualization of astronomical phenomena. In this study, a digital planetarium was used to teach the phases of the Moon to children aged 12 to 14 . To fully grasp the lunar phases, one must imagine the spherical Moon (as perceived from space), revolving around the Earth while being illuminated by the Sun, and then reconcile this view with the geocentric perspective. Digital planetariums allow learners to have both an allocentric and a geocentric perspective on the lunar phases. Using a Design experiment approach, we tested an educational scenario in which the lunar phases were taught in an allocentric digital planetarium. Based on qualitative data collected before, during, and after the planetarium intervention, we were able to demonstrate that five out of six participants had a better understanding of the lunar phases after the planetarium session.
\end{abstract}

Keywords Astronomy teaching · Digital planetarium · Full-dome · Phases of the Moon · Development research $\cdot$ Design-based research

\section{Introduction}

The phases of the Moon is a difficult concept to understand. Primarily, our limited and exclusively geocentric point of view of the Sun-Earth-Moon system (SEM) (Nussbaum 1985; Black 2005), our incorrect perception of the relative sizes and distances of astronomical objects (Miller \& Brewer 2010), and our difficulty to mentally shift away from Earth's frame of reference (Gazit et al. 2005), all prevent us from recognizing the intrinsic three-dimensional

P. Chastenay $(\bowtie)$

Département de Didactique, Université du Québec à Montréal, CP 8888 Succursale Centre-Ville, Montréal, Québec, Canada H3C 3P8

e-mail: chastenay.pierre@uqam.ca 
nature of the mechanism behind this phenomenon. These difficulties lead to a "plethora of different, more or less complicated conceptions" (Roald \& Mikalsen 2001, p. 236) held by students of different ages and cultural backgrounds about the lunar phases (see work by Baxter 1989; Philips 1991; Schoon 1992; Sharp 1995, 1996; Sharp et al. 1999; Stahly et al. 1999; Dunlop 2000; Liu 2005; LoPresto \& Murrell 2011; Comins, n.d.). Several teaching strategies that address misconceptions about the lunar phases have been tested in different educational settings, including using concrete SEM models in a traditional planetarium (Pitluga 1968; Bishop 1980; Rusk 2003), using concrete SEM models in a classroom environment (Kavanagh et al. 2005), using two-dimensional astronomy software on a computer (Trundle \& Bell 2003, 2010), using or creating three-dimensional dynamic computer models of the SEM or the solar system (Barnett \& Morran 2002; Keating et al. 2002; Sun et al. 2009), or using a traditional planetarium presentation (Brazell \& Espinoza 2009). But one strategyusing an immersive digital full-dome planetarium to show a space-based, or allocentric (from the Greek prefix allo-, meaning "different"), perspective on the lunar phases - has not been explored yet. In this paper, we will describe our first attempt to teach the phases of the Moon to students aged 12 to 14 years old by showing them an allocentric point of view of this phenomenon (Chastenay 2007, 2013).

\section{Traditional vs. Digital Planetarium}

In a traditional planetarium, an opto-mechanical star projector (OMSP) located at the center of a hemispheric chamber uses pinhole technology and lenses to project thousands of points of light onto an overhead domed screen (Chartrand 1973; Lowry 1984). These points of light are arranged so as to represent the stars and constellations visible with the naked eye from any point on Earth's surface. In addition, an OMSP uses motors and gears to simulate the apparent movements of the sky (diurnal and annual) and motorized add-on projectors to show the apparent diurnal and annual motions of the Sun, Moon, and naked-eye planets. Most current OMSPs can also simulate eclipses of the Sun and Moon, as well as the lunar phases. These phenomena are perceived by spectators inside the darkened planetarium chamber as a realistic and accurate representation of the sky as viewed from anywhere on the surface of our planet (a geocentric view). The simulation is also able to move back and forth in time at various speeds to simulate, in a few minutes, phenomena that would otherwise take weeks or months to unfold (e.g., the lunar phases, the seasons, the retrograde motion of Mars, etc.).

Since 1983, a growing number of planetariums worldwide have developed full-dome digital video projection capabilities (Faidit 2009; Petersen 2013). These planetariums use video projectors, computers, and graphic cards, three-dimensional navigation software, astronomical algorithms that calculate the position of solar system objects, and large astronomical database of stars and galaxies (Lantz 2002, 2007) to replace the traditional OMSP (Ruiz \& Acker 2006). Of course, the same geocentric simulations described above are still possible with this new equipment, but the digital nature of the projections and the use of threedimensional navigation software in a simulated astronomical universe make it possible to overcome the major limitation of the traditional planetarium-i.e., an exclusively geocentric point of view of the sky - and allow a shift from a geocentric to an allocentric perspective on the universe. Contrary to the traditional planetarium, which is limited to presenting a simulation of the sky as seen from the Earth's surface, the digital full-dome planetarium is an allocentric machine, capable of showing the audience the view from space, like in a virtual spacecraft (Abbott et al. 2004). Coupled with the "immersiveness" and the feeling of presence provided by the large hemispheric dome that completely fills the users' field of view (Prothero 
\& Hoffman 1995; Lin et al. 2002; Tan et al. 2003, 2004), this feature turns the digital planetarium into a powerful virtual environment (VE) (see McLellan 1996, and Youngblut 1998, for a more complete description of this technology), isolating the audience from the outside world and taking them to places that would otherwise be completely impossible to reach in the real world (Winn 1993, 2002). According to Yu (2005, p. 6), "the combination of VE and full-dome technologies [in a digital planetarium] results in a unique opportunity for astronomy instruction that is not possible in any other milieu."

\section{Teaching the Lunar Phases in an Allocentric Planetarium}

In this paper, we will explore this "unique opportunity" outlined by Yu (2005). More precisely, we want to test the idea that "visualisations that dynamically show astronomical phenomena from multiple vantage points, coupled with a curriculum explicitly designed to address popular misconceptions, have the potential to be powerful educational tools" (Yu \& Sahami 2007, p. 144). Here, we will discuss our findings, using a digital full-dome planetarium to teach the phases of the Moon to children aged 12 to 14 years old by showing them an allocentric point of view (i.e., the view from space) on the Moon and its orbital motion around Earth.

Since this is a pilot study in the relatively new and unexplored field of astronomy education using an allocentric digital full-dome planetarium (see the "Previous Research"), we decided to use a design experiment approach (Cobb et al. 2003, see the "Methodology"). As such, this paper will only present qualitative results of the first implementation of an educational scenario with six participants to teach the lunar phases in an allocentric digital planetarium. Future iterations of the scenario, to be conducted at a later date, will lead to a more quantitative approach with larger groups. For now, we are mainly interested in the fine details of the evolution of participants' conceptions about the lunar phases that could be triggered by showing them an allocentric perspective on the Moon and its orbital motion.

\section{Goals and Limitations of the Study}

Because of the limited amount of time participants had under the planetarium dome to address the challenging concept of the lunar phases $(90 \mathrm{~min})$ and the small number of participants involved, this study has many limitations. Of course, it is not possible to generalize the results of this first study, due to the small number of participants and the exclusively qualitative data that was collected. Also, it is not possible to distinguish between the effects of various components of the digital full-dome planetarium experience (for instance, the effects of immersion and allocentrism and the presence of a live instructor to guide learners through the simulation). Moreover, it must be noted that our goal is not to compare teaching the phases of the Moon in an allocentric digital full-dome planetarium to other modes of teaching (e.g., classroom instruction using concrete models, two-dimensional astronomy software and threedimensional computer models, or the traditional planetarium); rather, we want to explore the evolution of participants' misconceptions when exposed to different allocentric points of view on the lunar phases in an immersive virtual environment. We also want to find the best ways to scaffold the participants' experience via an educational scenario that will provide the necessary help along the way, eventually creating a learning experience in an allocentric digital planetarium that will help participants gain a better understanding of the mechanism of the lunar phases. 


\section{Previous Research}

Despite the promising educational potential of the digital full-dome planetarium (Yu 2005), very few research papers concerning its use in astronomy education to show a space-based (allocentric) perspective on astronomical phenomena have been published so far. Most studies have focused instead on the "immersiveness" of this new medium.

For instance, Yu et al. (2010) have studied the use of a digital full-dome planetarium as an immersive virtual environment to teach college undergraduates several astronomy topics, including the phases of the Moon, eclipses, and the seasons. Results of their study about teaching the seasons in a digital full-dome planetarium (Yu et al. in press) show that a demonstration of seasonal changes in an immersive digital planetarium, presenting an Earth-based point of view as well as a space-based perspective on Earth revolving around the Sun, leads to a better understanding of the mechanism of the seasons by college undergraduates than a similar visualization projected on a flat screen in a normal classroom, or no visualization at all. The authors attribute this result in part to the "immersiveness" of the planetarium session, as opposed to the flat-screen presentation, but also to the various points of view on the mechanism of seasonal changes provided by the digital virtual environment, although their study does not allow us to distinguish between both characteristics. Results of similar studies for other astronomical concepts with strong spatial components, like the lunar phases and eclipses, are not published yet, but are forthcoming (Yu 2014, personal communication).

Sumners et al. (2008) documented the educational impact of a pre-recorded 22minute, full-dome digital show about basic earth science concepts on the short-term knowledge increase of children in grades 3 to 12. Even though their study was more concerned with immersion than presenting various points of view of astronomical systems, they concluded that "an immersive planetarium theater can be an effective as well as engaging teaching method for Earth and Space science concepts, particularly those concepts that are intrinsically three-dimensional and thus most effectively taught in an immersive environment" (Sumners et al. 2008, p. 1848). In a continuation of the previous study, Zimmerman et al. (2014) compared the presentation of a 24-min show about human space flight in an immersive digital full-dome planetarium to the same presentation on a computer screen. Again, they found that the "immersiveness" of the planetarium dome resulted in better learning than the computer screen, both immediately after the presentation and 6 weeks later. However, their study did not involve a presentation of various perspectives on astronomical phenomena.

The studies presented above documented the educational potential of "immersiveness" in a digital full-dome planetarium for teaching astronomical concepts, but they did not address the possibilities offered by the allocentric perspective that this medium can provide, leaving many questions to be explored about allocentrism in a digital planetarium. For instance, what is the effect of presenting an allocentric perspective on astronomical systems on learners' mental models? What is the effect of allocentrism on the evolution of their misconceptions? What are the best allocentric perspectives on astronomical phenomena to show, in order to foster conceptual evolution toward the accepted scientific models? What is the best way to link the geocentric view of astronomical systems with the allocentric view from space? What is the best type of scaffolding to provide to learners when they are immersed in a simulation? These are some of the general questions that we wish to explore in this study. 


\section{Theoretical Framework}

It is a commonly accepted idea in science education that learners construct their own personal understanding of the workings of the world through direct interactions with the physical universe around them (Thouin 1997). This has a major impact on astronomy teaching because of our exclusively geocentric perspective on the sky. Nussbaum (1985) and Black (2005) have argued that this exclusively geocentric point of view on the universe, coupled with our inability to judge the scales and distances of astronomical systems, is the source of many misconceptions encountered in astronomy education. For the vast majority, these misconceptions are at odds with the current scientific view on these topics (Driver 1981); they are usually resistant to teaching and may survive unaffected until adulthood (Thouin 2004). The phases of the Moon are no exception, and misconceptions about the changing appearance of our satellite have been surveyed over the past four decades with students of all ages, from elementary school to college and university, and among pre- as well as in-service teachers (see references in the "Introduction"). Research has shown that the most prevalent misconception about the lunar phases is that phases occur because Earth or another object casts a shadow on the Moon or hides part of our satellite from view.

According to Vosniadou and Brewer (1994) and, more recently, Brewer (2008), individuals construct mental models from an early age to make sense of the world around them. These models evolve with new information and experiences, leading to highly personal mental models that are resistant to change as long as they remain useful. But faced with discrepant events or observations that challenge their mental models, individuals may feel dissatisfied with their current models, prompting them to consider a new model, as long as it is intelligible, plausible, and fruitful (Posner et al. 1982). This mechanism of conceptual change is the core of many teaching strategies in science education, and it is the one we will adopt in this research.

If our exclusively geocentric point of view on the sky is the source of so many misconceptions in astronomy, could a change in perspective from geocentrism to allocentrism provoke the evolution of misconceptions toward the scientific model? Could providing a space-based point of view on the SEM help learners see the limitations of their current mental models and foster conceptual change to build a mental model that is closer to the scientific view? Like many other astronomical phenomena, the phases of the Moon require, to be understood, the ability to visualize the Moon from different points of view, both geocentric and allocentric (Barnett et al. 2005; Gazit et al. 2006). According to Sadler (1992, p. 103), "without the ability to imagine what objects look like from different perspectives, students will find many astronomical concepts virtually impossible to learn." The recent development of immersive digital visualization tools - first in the domain of virtual reality (Youngblut 1998), then in the world of planetariums (Lantz 2002, 2007) — offers the possibility to show what astronomical objects look like from different perspectives, thus removing the cognitive burden on learners who no longer have to imagine what these systems look like. According to Psotka (1995), the use of immersive technology in education is a profound paradigm shift since it allows us to use our sense of vision (which naturally provides the most information on our environment) in a highly realistic simulation. As such, immersive technology and the various points of view it provides may facilitate learners' construction of accurate three-dimensional dynamic mental models of astronomical systems where positions, movements, and interactions are represented more naturally and more simply (Yair et al. 2001). 
Moreover, Winn (1993) notes that the psychological processes that are active when learners construct their understanding in immersive virtual environments are very similar to those used when they interact with objects and events in real life; the use of immersive simulations to present various perspectives on an astronomical phenomenon like the phases of the Moon could thus lead to a more direct, more natural, and more lasting learning than those mediated by two-dimensional interfaces (images, diagrams, or computer screens) or three-dimensional models. Indeed, learning fostered by semi-immersive and immersive technologies presenting different points of view of various dynamic systems has been demonstrated in several virtual environments, including the surface of a small asteroid to teach the spherical shape of Earth (Ohlsson et al. 2000), a saltwater bay to teach hydrology (Windschitl et al. 2001), a CAVE ${ }^{\mathrm{TM}}$ virtual environment to teach chemical reactions (Limniou et al. 2008), and a virtual university campus to teach the GPS localization system ( $\mathrm{Li}$ et al. 2010).

\section{An Educational Scenario to Teach the Lunar Phases in an Allocentric Planetarium}

As noted by Bakas and Mikropoulos (2003) and Gazit et al. (2005), learners exploring any technology-based simulation need an educational scenario that provides them with guidance and scaffolding while they are immersed in the simulation, to avoid the emergence of new or hybridized misconceptions. "Indeed, one may infer that the emergence of misconceptions is a direct consequence of the lack of such mentoring. A well-thought-out interaction with a teacher or a built-in smart agent could reduce or prevent them" (Gazit et al. 2005, p. 468). Thus, a well-thoughtout educational scenario is required to accompany learners throughout their interaction with the technology.

For this study, we created an educational scenario that guided learners throughout their exploration of the lunar phases (see Appendix for a description of the scenario). First, we observed the lunar phases from a geocentric perspective for the equivalent of 1 month (speeded up to a few minutes), and participants were invited to sketch the daily aspect of the Moon on their moon calendar. Indeed, we cannot take for granted that all learners are familiar with the astronomical phenomena we are trying to teach (Trundle et al. 2006). In the case of the lunar phases, most children are probably aware of the fact that the Moon's appearance changes over time, but few know that the changes are systematic and cyclic. Observing the Moon for a month provided learners with basic knowledge about the sequence and nomenclature of the Moon's phases, but it also provided a clear benchmark to compare with outcomes based on their own personal mental models of the lunar phases.

Second, we left Earth and showed the Moon in space (Fig. 1) and its orbital motion around Earth from different allocentric perspectives (Fig. 2). By presenting various space-based points of view on the Moon and the mechanism of the lunar phases along a continuous flight path, via the highly realistic simulation afforded by the digital planetarium, we were "[...] putting students in situations where they [had] to evaluate empirical evidence that [was] contrary to their beliefs" (Bakas \& Mikropoulos 2003, p. 959), thus creating dissatisfaction and prompting them to consider the simulation representing the scientific model as a valuable alternative (intelligible and plausible) to explain their previous observations. This set the stage for learners to experience discrepant events that "play an important role in challenging students to reconsider their pre-established views of how the universe works, and, in so doing, to make room in their mental frameworks for alternative explanations, which are more congruous with established scientific views" (Moore \& Huber 2001, p. 456). 


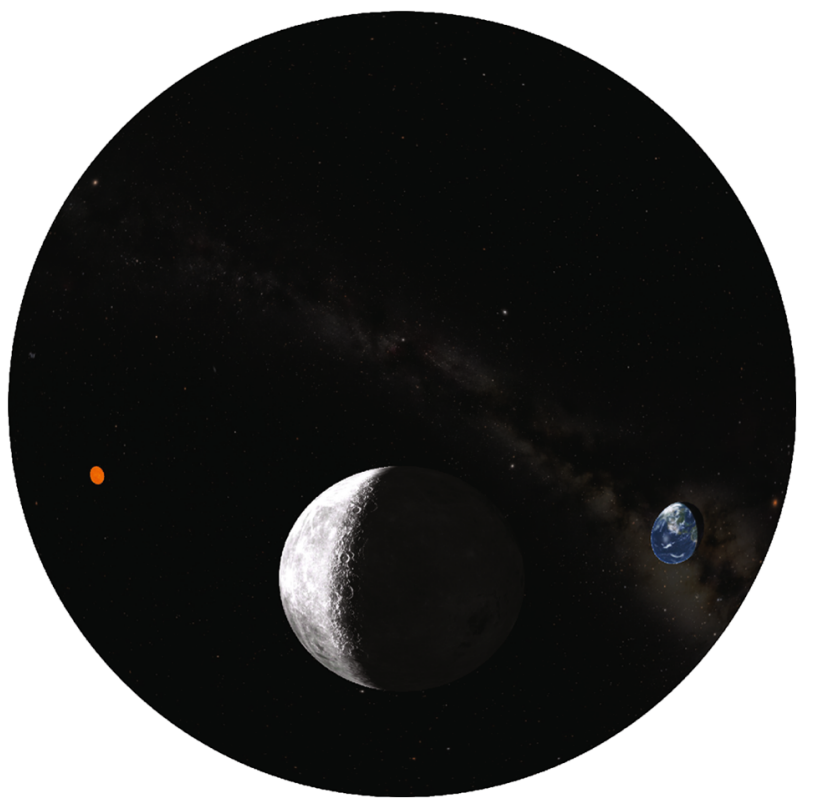

Fig. 1 Image excerpted from the allocentric digital full-dome planetarium session showing the Moon in space, with the Earth and Sun in the background. Note that the Moon is lit only on one side, like Earth, with the light coming from the Sun on the left. This frame is a dome master, a distorted circular image that produces an accurate immersive effect for the viewer when projected on the hemispherical surface of a dome planetarium (image courtesy of Sky-Skan Inc.)

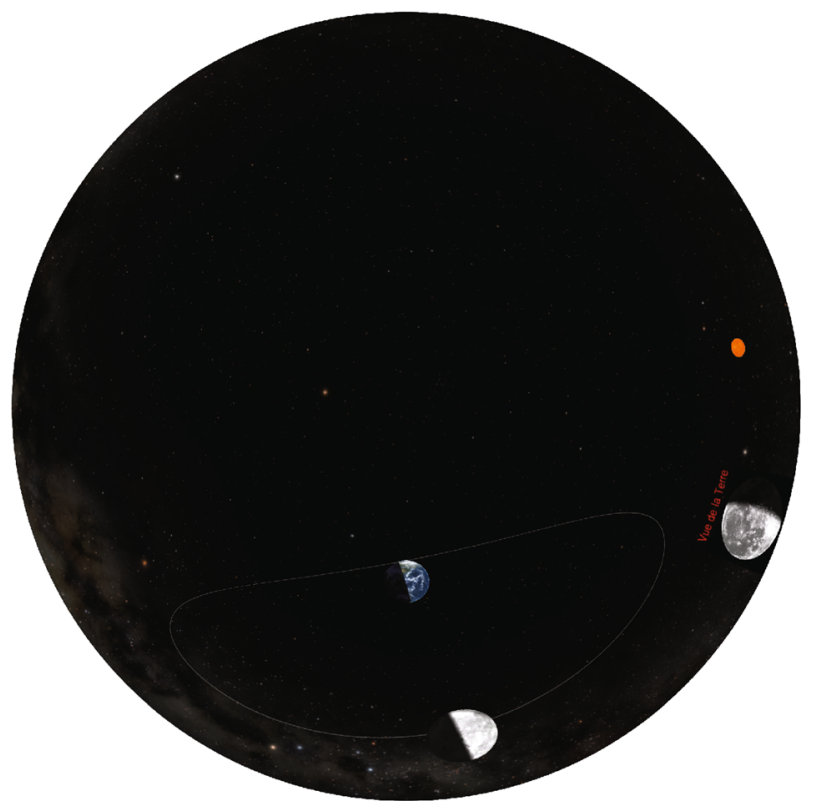

Fig. 2 Dome master image showing an allocentric perspective on the Moon's orbit, with an insert (Vue de la Terre, the view from Earth) showing the corresponding geocentric view of the lunar phases (image courtesy of Sky-Skan Inc.) 
The scenario also contained an explanation of the scientific model of the lunar phases, presented through instruction while learners were immersed in the simulation, as suggested by Rieber (2004), to highlight its most important features. In the case of the lunar phases, learners needed to realize that the Moon is spherical (like Earth); that it does not produce its own light, but rather is lit by the Sun (hence half the Moon is always bright and half is always dark, i.e., the Moon projects a shadow onto itself); and that it revolves around Earth in a little less than a month.

Learners also needed help to reconcile the view from space with the various phases they previously observed in geocentric mode. As noted by Rieber (2004), scaffolding can take many forms, such as "exercises, questions and even games, [that] help students learn from the simulation" (p. 599). Through dialogue between the instructor and the participants, learners were asked to make predictions and compare them to a view of the simulation (Fig. 3), forcing them to apply their mental models to a realistic situation to see if they matched or not (Plummer 2009). Sadler (1992) reports that "[...] experiences of wrongly predicting events are not detrimental, but rather can be beneficial. They provide the motivation for students to explore the inconsistency and hold the potential for students to change their ideas" (p. 16).

Lastly, learners were presented with new circumstances where the scientific model of the phases could also be applied, to show its fruitfulness. We demonstrated the phases of Venus as seen from Earth (Fig. 4) and the phases of Earth as seen from the near side of the Moon (Fig. 5). These provided learners with fresh and surprising situations (in the case of Earth's phases, at least) where the scientific model of the lunar phases could be called upon to explain new phenomena and predict the outcome of observations. We did this to reinforce the mental model of phases that participants

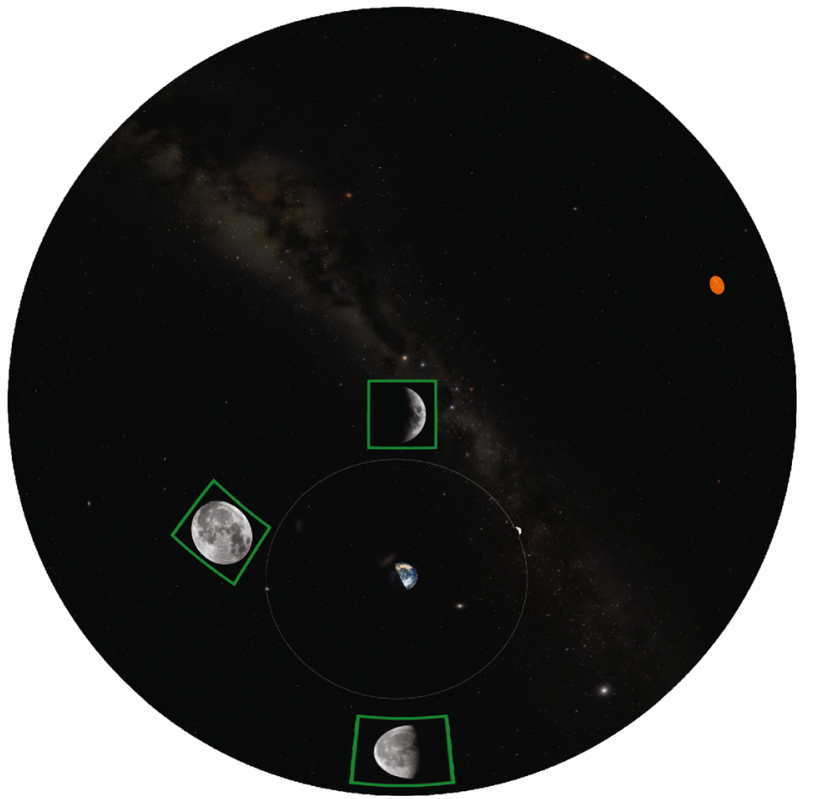

Fig. 3 Dome master image showing a polar view of the Moon's orbit. Every time the Moon was stopped on its orbital path, participants were asked to guess what the corresponding geocentric aspect of the Moon (its phase as seen from Earth) was. They were then shown a picture of the Moon's phase (green frames) taken by a friend back on Earth with her telescope (image courtesy of Sky-Skan Inc.) 


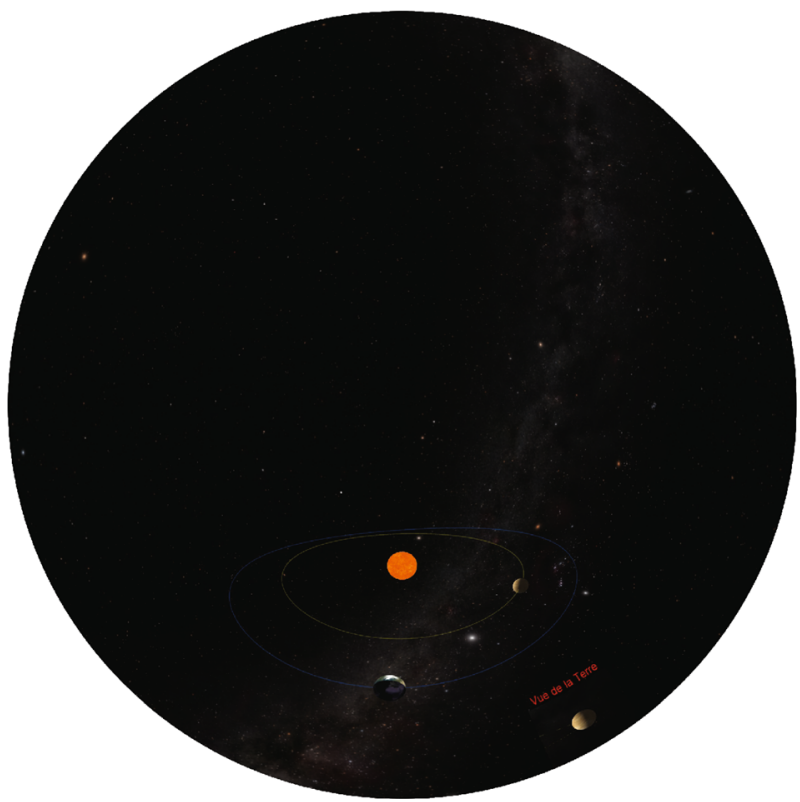

Fig. 4 Dome master image showing an allocentric view on the phases of Venus, with an insert showing the corresponding view from Earth (image courtesy of Sky-Skan Inc.)

had built based on the new, allocentric imagery, and convince them that this model worked in several different settings.

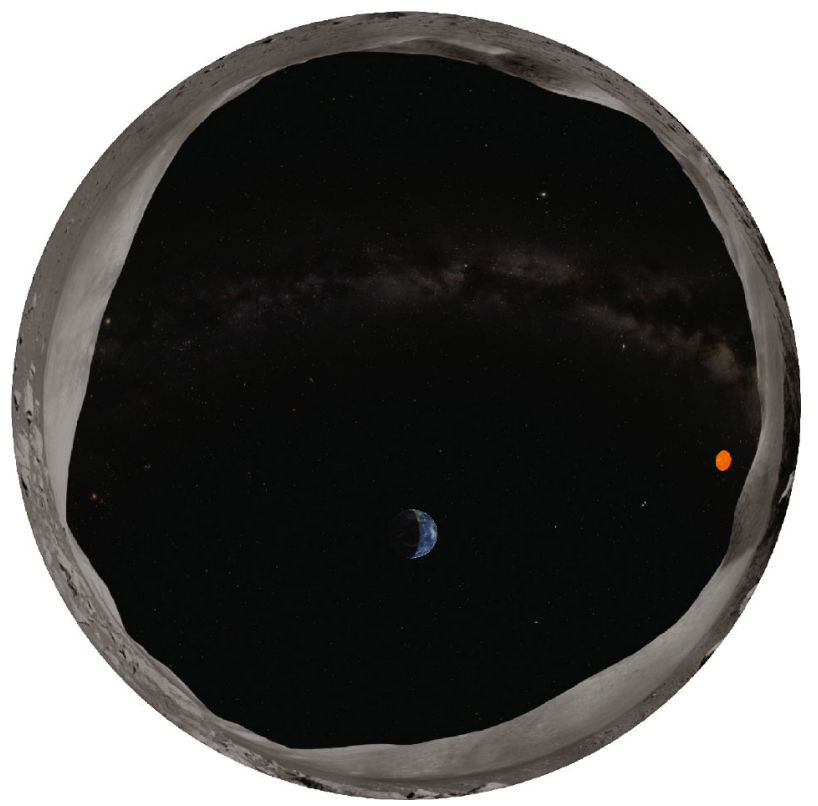

Fig. 5 Dome master image showing the phases of Earth as seen from the near side of the Moon. Note the Sun on the right (image courtesy of Sky-Skan Inc.) 


\section{Methodology}

The work we are presenting here consists of an exploratory research in the relatively new field of astronomy education using a digital full-dome planetarium to show an allocentric perspective on astronomical systems. Our goal is to develop and test the educational scenario previously described, allowing it to evolve through several implementation cycles. To reach this goal, we chose a methodological approach that goes by several different names, such as design experiment (Cobb et al. 2003), design science (Gorard et al. 2004), design-based research (Design-Based Research Collective 2003), or design studies (Shavelson et al. 2003) (see also National Research Council 2002). Shavelson et al. (2003) describe design study as a cyclic methodology that focuses on the learning process, that is interventionist and collaborative by nature, that is willing to influence the broader institutional context where it is applied, that puts emphasis on the effectiveness of the educational interventions, and that is willing to improve theory through practice. In the following, we will use the terms design experiment to describe our methodological approach.

Design experiment is based on two complementary approaches. The first approach, deductive, reviews relevant research literature to come up with a combination of theoretical and practical solutions to design the teaching intervention. The second approach, inductive, is based on the results of successive implementations and testing of the intervention in its "natural" setting (Van der Maren 1996; Gorard et al. 2004). The combination of these two approaches allows the conception, testing, and improvement of a teaching intervention in its natural context, all the while allowing its theoretical foundation to evolve with new hypotheses and new ideas emerging from the intervention, thus enriching further implementations of the intervention through informing cycles (Design-Based Research Collective 2003). In the following section, we will present the results of the first implementation of our teaching intervention.

Although several design experiment researchers suggest evaluating the first implementations of the educational intervention through a variety of methods, both qualitative and quantitative, we decided to follow Artigue (1996) and Shavelson et al. (2003), who note that the early stages of a design experiment are generally more exploratory in nature, less focused, with broader research questions, and thus are better served by the collection of qualitative data that will give a more detailed account of the educational effects of the intervention.

In this study, since we are presenting the results of the first implementation of our educational intervention, only qualitative data concerning the evolution of participants' conceptions about the lunar phases was gathered and will be presented. Pre- and postintervention data was collected using the same instruments, including individual and group interviews; a written questionnaire with open-ended and multiple-choice questions; flashlight and balls of different diameters (a concrete model of the SEM); and pictures of various lunar phases. For the multiple-choice questions, possible answers contained distractors corresponding to common misconceptions (Treagust 1988). According to Sadler (1998, p. 287), "distractor-driven multiple-choice questions which pit students' previous ideas versus scientific views are very effective in examining conceptual change."

To ensure the external validity of our questionnaire and other materials, we asked four professional astronomers at the Université de Montréal to review them. They all agreed that the questions were clear and that there was only one correct answer to each multiple-choice question. They also found the other materials (balls, pictures, etc.) appropriate for their intended use. To ensure the internal validity of our research, we interviewed participants on each topic relevant to the lunar phases several times using different modes of questioning 
(multiple-choice and open-ended questions, sketches, verbal descriptions, model making, etc.), and found that each individual gave consistent answers throughout. We also asked another researcher to verify the interpretive validity of our work by independently reviewing the data collected and confirming our analysis and conclusions (Thouin 2012, personal communication). Lastly, by comparing pre- and post-intervention results with data collected during the planetarium intervention itself, we were able to track in finer detail the evolution of participants' conceptions about the phases of the Moon.

Our educational intervention was tested on 7 July 2012, with six children aged 12 to 14 years old (four boys, two girls). Several authors agree that the lunar phases are an appropriate topic for students of that age group (Tomlinson 1997; Stahly et al. 1999; Bishop 2002; Taylor et al. 2003; Barnett \& Morran 2002; Kavanagh et al. 2005). The six volunteer participants were recruited from among the children of colleagues who work for a large science museum complex where the author also worked, but was not in direct, day-to-day contact with the children. Participants are presented in Table 1, under pseudonyms.

We did not collect background information on the participants apart from what is presented in Table 1. The main reason for this is, again, the exploratory nature of this first iteration of our educational intervention, and the fact that we are mainly interested in the comparison of pre- and post-intervention results to track the evolution of participants' conceptions when confronted with an allocentric perspective on the lunar phases. For these reasons, other information on participants (previous planetarium visits, astronomy education at school, etc.) was not considered useful at this stage of the research.

The planetarium session was conducted under a 6-m-wide inflatable dome (Fig. 6). A video projector equipped with a single fish-eye lens occupied the centre of the dome and projected onto the hemispheric screen a full-dome image produced in real time with Sky-Skan's DigitalSky $2^{\mathrm{TM}}$ software. A digital audio recorder and a video camera were used to record pre- and post-intervention sessions held in an adjacent meeting room, while two microphones were located under the dome to record conversations during the planetarium session. The instructor (the author) also took notes during the presentation to help analyze at a later date comments made by participants under the dome. All recordings (in French) were transcribed by the author. Table 2 presents the schedule of our intervention and the duration of each segment. In total, the entire intervention lasted $3 \mathrm{~h}$, including $90 \mathrm{~min}$ under the planetarium dome.

Previously, we identified several general questions that we wanted to explore through the present research concerning the presentation of an allocentric point of view on the lunar phases in a digital planetarium. More specifically, the first iteration of our intervention to teach the

Table 1 Name (pseudonym), gender, and age of participants to the study

\begin{tabular}{lll}
\hline Name (pseudonym) & Gender & Age \\
\hline Adam & Male & 12 \\
Benoît & Male & 13 \\
Bernard & Male & 12 \\
Louis & Male & 12 \\
Maude & Female & 14 \\
Nadine & Female & 12 \\
\hline
\end{tabular}




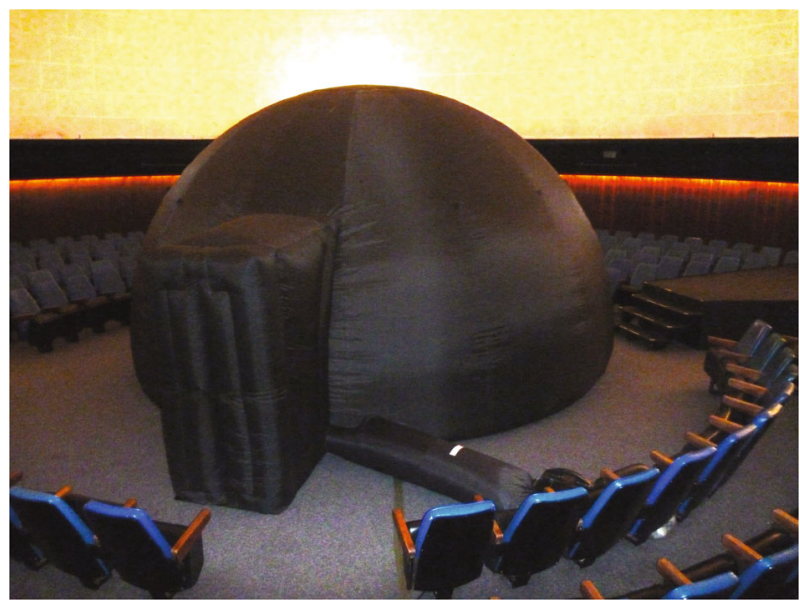

Fig. 6 The 6-m inflatable dome where the planetarium session was conducted, sitting at the center of the 20-m theater of the now closed Planétarium de Montréal (image courtesy of the author)

phases of the Moon in an allocentric digital full-dome planetarium was conducted in order to answer the following research questions:

1. What conceptions about the lunar phases did participants have before experiencing the educational intervention in the allocentric digital full-dome planetarium used to teach the phases of the Moon?

2. How did participants' conceptions about the lunar phases evolve during and immediately after experiencing the educational intervention in the allocentric digital full-dome planetarium?

3. What aspects of the educational intervention in the allocentric digital full-dome planetarium did participants appreciate the most? What aspects did they appreciate the least?

Table 2 Intervention schedule and duration of each segment

\begin{tabular}{|c|c|c|}
\hline Phase & Description & Duration (min) \\
\hline Presentation of the research & $\begin{array}{l}\text { Overview of the goals of the research and the schedule } \\
\text { of the intervention, presentation of participants }\end{array}$ & 5 \\
\hline Pre-test & $\begin{array}{l}\text { Written questionnaires, individual and group interviews, } \\
\text { picture-sorting, and modelization of SEM }\end{array}$ & 30 \\
\hline Break & & 5 \\
\hline $\begin{array}{l}\text { Presentation of the digital } \\
\text { full-dome technology }\end{array}$ & $\begin{array}{l}\text { Demonstration of the inflatable dome, computer and } \\
\text { video projector }\end{array}$ & 10 \\
\hline Planetarium session & $\begin{array}{l}\text { Observation of lunar phases from Earth, observation } \\
\text { from space, phases of Venus, phases of the Earth }\end{array}$ & 90 \\
\hline Break & & 15 \\
\hline Post-test & $\begin{array}{l}\text { Written questionnaires, individual and group interviews, } \\
\text { verbal explanation of the mechanism of lunar phases }\end{array}$ & 30 \\
\hline Post-test discussion & $\begin{array}{l}\text { Suggestions by participants of ways to enhance the } \\
\text { planetarium session }\end{array}$ & 15 \\
\hline Total (excluding breaks) & & 180 \\
\hline
\end{tabular}


4. How can the educational intervention in the allocentric digital full-dome planetarium be improved, based on the results of its first implementation?

\section{Results and Discussion}

In the following sections, we present the qualitative data that was collected before, during, and after the allocentric planetarium session used to teach the phases of the Moon. The comparison between comments and answers from participants at different stages of the educational scenario will help us track the evolution of their conceptions of the lunar phases throughout the intervention. We have organized the following presentation into four broad learning categories, each referring to a particular set of knowledge about the Moon, the lunar phases, and the phenomenon of phases in general:

1. The lunar phases as seen from Earth (the aspect of the lunar phases as seen from Earth, the sequence of the phases over 1 month, and nomenclature of the lunar phases).

2. The Moon as an astronomical object (the shape of the Moon, the source of its illumination, and its movements in space).

3. The mechanism of the lunar phases (participants' written and verbal descriptions).

4. Participants' transfer (reinvestment) of the lunar phase model to other phases.

Each sub-section will be followed by a short summary of the major findings.

The Lunar Phases as Seen from Earth

Aspect of the Lunar Phases as Seen from Earth: In the written questionnaire, we asked participants to "draw all the shapes that you know the Moon could have. You can draw as many shapes as you can think of." Results of the pre-test sketches are presented in Fig. 7a; results of the post-test, in Fig. $7 b$.

In the pre-test, we noted the presence of several non-scientific phases, such as Adam's and Benoit's second and third moons from the left, which depict partial eclipses of the Moon rather than phases, and Bernard's and Maude's full moon with craters, reminiscent of the naïve illustrations found in children's books. Bernard's three crossed-out moons might be an indication of his lack of confidence in drawing the Moon's phases. Only Maude and Nadine seem to have attempted to draw a valid sequence of the Moon's phases (Nadine's note in French, pareil de l'autre côté, translates as "same on the other side"), even though the waxing and waning phases are inverted in their sketches. We noted that Adam, Bernard, Benoit, and Louis drew only full and waning crescents, a result consistent with what Trundle and Troland (2005) and Trundle et al. (2008) found in children's books and drawings of the Moon by children and adults. Lastly, only Maude and Nadine drew gibbous moons, and no one drew a new moon.

The situation evolved considerably following the planetarium session (Fig. 7b). First, we noted that participants drew $38 \%$ more phases after instruction (34 phases on the pre-test, including crossed-out moons, compared with 47 on the post-test). This indicates that observing the Moon systematically for one lunation - the first activity conducted under the planetarium dome - provided participants with more mental images of the Moon's phases than they had prior to instruction. We also saw a more systematic use of the darkening of the Moon to 
Fig. 7 a Participants' pre-intervention sketches of all the shapes the Moon could have. b Participants' post-intervention sketches of all the shapes the Moon could have a

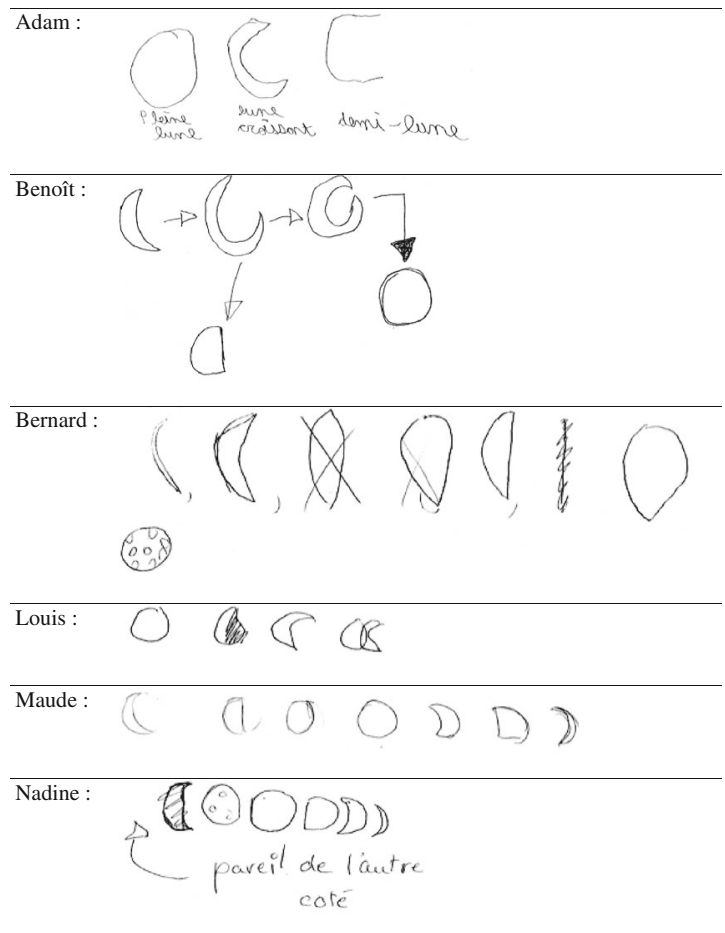

b
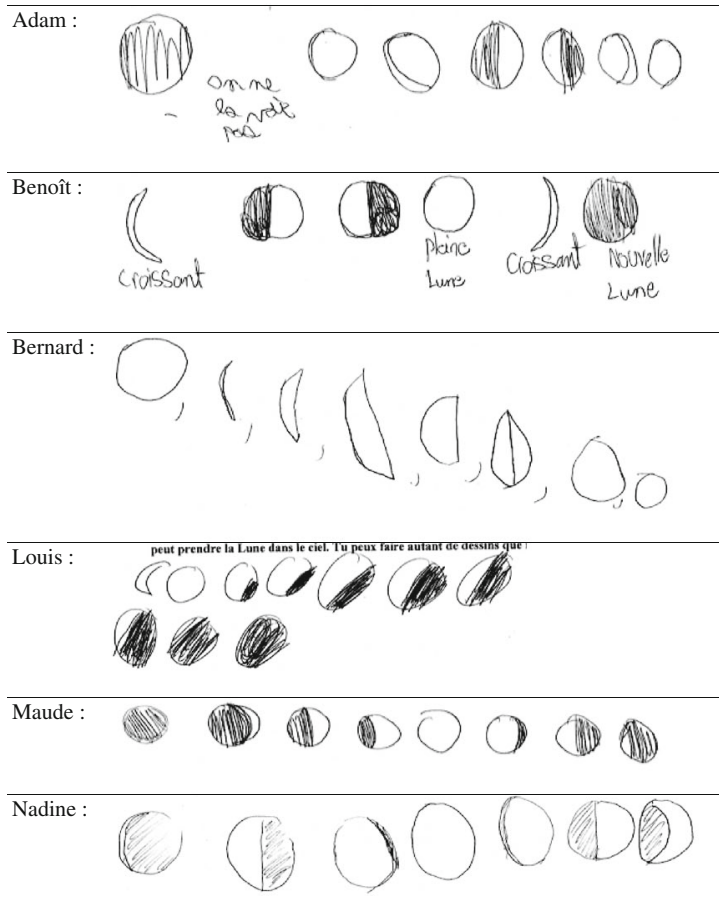
illustrate partial phases, a consequence of the method used by participants to draw the phases on their moon calendar during the planetarium session. We interpret this as a sign that participants now considered the Moon to be a three-dimensional object, a sphere whose bright half is seen from different angles, an important aspect of the scientific explanation of the lunar phases that was covered during the planetarium session.

In Fig. $7 \mathrm{~b}$ drawings, the non-scientific phases have disappeared and four out of six participants drew new moons (we interpret Adam's note, On ne la voit pas, which translates as "We don't see it," to indicate the new moon). The absence of a new moon in Nadine's sketches, given the presence of all the other phases, may simply indicate that she did not bother drawing something we cannot see. Gibbous phases were drawn by all participants, except Benoît. We note, however, that Louis's terminator is always a straight line (an instance that only occurs during first and last quarter), and Maude's fourth and eighth moons have inverted terminators. Participants' sketches also showed a better distribution of the waxing and waning phases, except for Bernard's and Louis' exclusively waning crescents. There were also clear attempts by Bernard, Louis, Maude, and Nadine to draw the correct sequence of phases. Maude's sequence of phases is correct, with the waxing and waning phases in the right order. Nadine's is also correct if read from right to left. Lastly, we note the use of the right nomenclature in Benoît's sketches. These findings lead us to conclude that participants had a much better knowledge of the sequence of the lunar phases after the dome session.

Sequence of the Lunar Phases Over 1 Month: During the pre-test, participants were asked to work as a team to sort eight pictures showing the different phases of the Moon (a completely black picture represented the new moon) and put them in the order that they thought would show the sequence of the lunar phases as seen from Earth over 1 month. It should be noted that, although astronomers usually designate new moon as the starting point of the lunar cycle, this is a completely arbitrary choice and, as long as the order of the phases is respected, the particular phase that participants decided to start the cycle at is irrelevant and was not considered when reviewing their answers.

Bernard took the lead by stating that the new moon must be at the beginning or end of the cycle, and the full moon should be in the middle. Everyone agreed with this idea, except Benoit, who claimed that if the new moon was at the beginning of the cycle, then the full moon should be at the end. The following dialogue ensued:

Bernard: What I mean is . . the new moon, you all agree with me that it can be at the beginning or the end [of the cycle].

Benoit: And the full moon can also be at the beginning or the end.

Bernard: The full moon can be the beginning or the end, all right, but I would put it in the middle, so it begins with the new moon and then [the Moon] grows . . .

Benoît: Ok, but what about the full moon? It must be the end because the full moon is complete. It's full!

From that last remark, we presume that Benoît thought the phases of the Moon began with the new moon and "grew" until the Moon was full, as if filling up like a jar. In fact, moments after the other participants agreed on their sequence, illustrated in Fig. 8a, Benoit shuffled the pictures again to create his own sequence, illustrated in Fig. 8b, where the Moon grows gradually from new to full. (Note that in both cases, some pictures are upside down, since participants did not pay attention to the proper orientation of the images at this stage.) Benoit further clarified his idea by comparing the Moon to an orange, whose disassembled pieces can be put back together until they form a round fruit. Benoit's conception of the Moon filling up 
$\mathbf{a}$


b
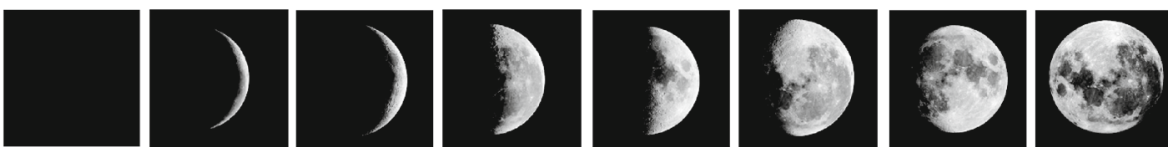

Fig. 8 a Sequence of the lunar phases established by all participants, except Benoit. b The phases of the Moon according to Benoît and his "filling-up" model

might be derived from the vocabulary, with the assumption that the Moon becomes "full" after having been filled up ("full moon" translates as pleine lune in French and has the same meaning) or reassembled from several "slices" that are put back together. This conception is quite unique and, to the best of our knowledge, has never been documented in literature before.

The sequence agreed on by the other participants (Fig. 8a) is in reverse order, with the waxing and waning phases inverted. However, it still follows the logic of the Moon growing larger from new to full, and then shrinking from full to new. All participants were satisfied with their sequence, except Benoît, who clearly had his own idea. Due to the tight schedule, this sorting activity was not reproduced during the post-test discussion, but was replaced with each individual being asked to explain the mechanism of the Moon's phases in his or her own words. The results of this activity will be described later.

During the planetarium session, while watching the sequence of the lunar phases over the course of 1 month, the Sun was right above the western horizon at one point and the full moon was in the East, so low that advancing one more day (annual motion) made it dip down and disappear below the horizon. That is when Benoît shouted, "It's the new moon!" Indeed, based on his "filling-up" model of the lunar phases, it made perfect sense for him that the day after the full moon, the Moon would become invisible again as the new moon. But the instructor quickly demonstrated that the Moon was simply below the horizon by advancing to midnight of the same day, which brought the full moon high above the southern horizon. Benoit was clearly puzzled, even more so as he watched the Moon wane day after day until it became a thin crescent in the morning sky, and then disappeared for a few days before another thin crescent reappeared in the evening sky.

Nomenclature of the Lunar Phases: Participants were asked to draw lines associating seven different lunar phases with their corresponding names (see Fig. 9). The results are displayed in Table 3. On the pre-test, only the full moon was correctly identified by all participants. Other frequent correct associations were the crescent moon and the new moon. Only Maude was able

Table 3 Number of correctly associated images and names of lunar phases out of a total of seven

\begin{tabular}{lll}
\hline Participant & Pre-intervention $(/ 7)$ & Post-intervention $(/ 7)$ \\
\hline Adam & 3 & 7 \\
Benoît & 2 & 5 \\
Bernard & 2 & 7 \\
Louis & 3 & 5 \\
Maude & 4 & 7 \\
Nadine & 2 & 5
\end{tabular}


Nom :

Âge :

À l'aide d'un trait, relie chaque photo de la Lune à gauche avec le nom de la phase correspondant à droite.

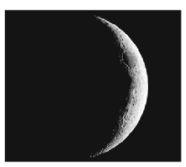

PLEINE LUNE

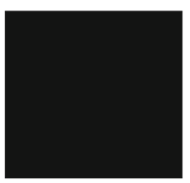

LUNE CROISSANTE

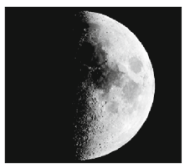

NOUVELLE LUNE

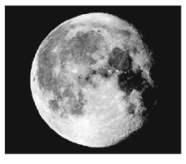

DERNIER QUARTIER

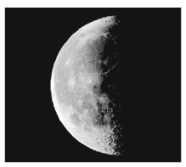

LUNE GIBBEUSE DÉCROISSANTE

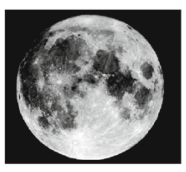

LUNE GIBBEUSE CROISSANTE

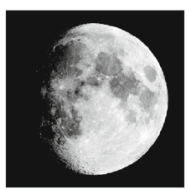

PREMIER QUARTIER

Fig. 9 Participants were asked to draw lines associating seven different lunar phases with their corresponding names 
to correctly identify four phases, including the difficult waxing and waning gibbous moons. On the post-test questionnaire, correct answers were much more numerous, with three participants out of six getting perfect scores. It should be noted that those who got five correct answers out of seven simply inverted the waxing and waning gibbous phases, a common error for these challenging phases. Participants who were not sure about which gibbous phase was waxing or waning had a 50-50 chance of getting it right simply by guessing, which might be what occurred. But even if there was some guessing involved in naming the gibbous phases, there was no guessing for the other phases, including the first and last quarter. This indicates that participants now had a much better knowledge of the nomenclature of the lunar phases, another consequence we associate with watching the Moon systematically over one lunation at the beginning of the dome session.

Summary: When comparing pre-test answers to post-test results, we see a clear increase in participants' knowledge of the various aspects of the lunar phases as seen from Earth. As expected, participants had a poor grasp of the different shapes of the Moon and the correct nomenclature of the lunar phases prior to instruction. Following the dome session, participants had a better knowledge of the different shapes of the Moon over 1 month and the names of the major phases. The naïve and unscientific phases no longer appeared in participants' sketches in the post-test questionnaire, and new moon and gibbous moons were much more numerous in the post-intervention answers. After the presentation of the geocentric view of the lunar phases over 1 month in the planetarium, participants had a much better knowledge of the phenomenon they now had to explain with their own mental model. All this supports the notion that it is important, before teaching the mechanism of any astronomical phenomena, to make sure that learners are familiar with its geocentric aspect. This gives them a set of mental images to compare with their own mental model and may help to provoke dissatisfaction with it, the first step toward conceptual evolution (Posner et al. 1982).

\section{The Moon as an Astronomical Object}

Shape of the Moon: In the written questionnaire, participants were asked, "In your opinion, what is the actual shape of the Moon? For instance, is it shaped like a crescent roll? Is it flat and round like a dinner plate or round like a ball? Does it have a different shape? Please elaborate." In the pre- and post-tests, all six participants answered that the Moon is spherical. The shape of the Moon as a spherical object was clearly not an issue for participants, even before the dome session, and that correct idea was reinforced during the planetarium session when we were in orbit around our satellite (see Fig. 1).

Source of the Moon's Illumination: Participants produced various written answers to the question, "Where does the light of the Moon come from?" (see Table 4; translated from French by the author). On the pre-test, the notion of the Moon reflecting light from the Sun seemed problematic for Benoît (who gave no answer, even after verbal prompting by the instructor) and Louis, even if he mentioned the Sun. The other participants gave valid answers, even though Bernard and Maude were not entirely sure of theirs. Interestingly, Nadine mentioned the Sun shining on only one part of the Moon, causing a change in shape, an important aspect of the scientific model of the lunar phases, but not entirely related to the question asked. In the post-test, we received much more precise and correct answers from all participants, a clear indication that this aspect of the mechanism of the lunar phases, dealt with in detail during the planetarium session, was now well understood. 
Table 4 Pre- and post-intervention answers to the question, "Where does the light of the Moon come from?"

\begin{tabular}{|c|c|c|}
\hline Participant & Pre-intervention & Post-intervention \\
\hline Adam & $\begin{array}{l}\text { The Sun puts light on the Moon and } \\
\text { sends it back toward Earth. }\end{array}$ & $\begin{array}{l}\text { The Sun reflects on the Moon and } \\
\text { the rays go to Earth. }\end{array}$ \\
\hline Benoît & (No answer) & $\begin{array}{l}\text { The Moon doesn't produce its own } \\
\text { light, it is rays from the Sun that } \\
\text { lit up the Moon and reflect toward } \\
\text { the Earth. }\end{array}$ \\
\hline Bernard & $\begin{array}{l}\text { I think at night, even if we don't see } \\
\text { the Sun, its light strikes the Moon } \\
\text { and the Moon reflects it. }\end{array}$ & $\begin{array}{l}\text { It is light form the Sun that reflect on } \\
\text { the Moon, because it is very bright. }\end{array}$ \\
\hline Louis & $\begin{array}{l}\text { I don't know where the light of the } \\
\text { Moon comes from, but I think it } \\
\text { enters into contact with the Sun } \\
\text { and stars. }\end{array}$ & It reflects light from the Sun. \\
\hline Maude & $\begin{array}{l}\text { I believe it reflects toward us the light } \\
\text { from the Sun. }\end{array}$ & It reflects light from the Sun. \\
\hline Nadine & $\begin{array}{l}\text { It's the light from the Sun. But why } \\
\text { [the Moon] doesn't always have the } \\
\text { same shape, it's because the Sun } \\
\text { light up only one part [of it]. }\end{array}$ & It is the Sun that light up the Moon. \\
\hline
\end{tabular}

Movements of the Moon in Space On the pre-test, participants were asked to use balls with different diameters to model the SEM and demonstrate its movements. They immediately decided that a golf ball should represent the Moon; a tennis ball, Earth; and a basketball, the Sun. They then proceeded to describe the revolution of the golf ball (the Moon) around the tennis ball (Earth), while at the same time the tennis ball was revolving around the basketball (the Sun). Their model showed that participants clearly understood that the Moon was revolving around Earth, and Earth around the Sun. Participants even modeled the rotation of our planet and that of the Moon, a concept that was referred to again during the planetarium session. However, rotations and revolutions were frequently clockwise, instead of counter-clockwise (as seen from above Earth's North Pole). To save time, this activity was not repeated in the posttest; we believed that participants had already demonstrated a sufficient grasp of the relative movements of the Moon in space to understand the mechanism of the lunar phases. In addition, the notion of the Moon's orbit around Earth and its connection with the changing aspect of the Moon as seen from Earth was revisited at length during the dome session (see Figs. 2 and 3).

Summary: Overall, even before the planetarium session, participants demonstrated a good knowledge of the Moon as a spherical object revolving around Earth, two very important notions to grasp in order to understand the mechanism of the lunar phases. But the Sun as the only source of the Moon's illumination was problematic for some participants before the dome session, a situation that evolved favorably after instruction in the planetarium. We think that, after the dome session, participants had the necessary knowledge and information to construct a correct mental model of the Moon and its movement in space.

\section{Mechanism of the Lunar Phases}

Described in Writing by Participants: In the written questionnaire, participants were asked to explain in their own words, "What makes the Moon change its appearance from day to day?" 
Pre- and post-intervention answers are reproduced in Table 5. Before instruction, four out of six participants struggled to explain the Moon's phases correctly. We did not receive an answer from Adam so we could not know what he was thinking, and verbal prompting by the instructor did not produce further explanation. Benoit gave a classical "eclipse-type" answer by suggesting that fog hides the Moon, whereas Louis linked the phases to the position of the Sun at sunset, but he did not seem very sure of his explanation. Nadine mentioned the Sun and shadow, which might have been a reference to eclipses to explain the lunar phases, a common misconception, or to the shadow the Moon casts on itself (i.e., a self-shadow), which is partially correct. Maude mentioned the rotation of the Moon, which is another frequent misconception, even though the rest of her explanation contained elements of the scientific model. Bernard thought the phases were related to the position of the Moon and the way it is lit up, which is correct, but he could not come up with a complete description of the mechanism of the lunar phases. Overall, the post-intervention answers were more accurate, and we observed conceptual evolution in four out of six participants (Benoît, Louis, Maude, and Nadine). Benoit, Maude, and Nadine all gave a comprehensive explanation after instruction that displayed a clear evolution of their conception of the lunar phases when compared with their pre-test answers. The evolution is particularly striking for Benoit, who mentioned fog prior to instruction, whose pre-test proposition for the sequence of the lunar phases (described earlier) seemed based on a completely novel conception of the Moon "filling up" from new to full, and who tried to explain the lunar phases by the rotation of the Moon during the planetarium session. Louis's postintervention answer referred to the position of the Moon, which is correct, but his explanation still lacked other elements of the mechanism of the lunar phases; his conception evolved, but not up to the scientific model. Bernard's answer was correct, but fell short of explaining the lunar phases (curiously, his pre-test answer was more accurate). This is surprising, given the way he spontaneously applied the scientific model of the lunar phases to other instances (Mercury, the satellites of Jupiter) during the planetarium session and post-test discussion (see next section), and also how he was able to correctly describe the mechanism of the lunar phases verbally (see below). Lastly, Adam progressed from "No answer" to "The Sun," an answer we cannot consider as a valid conceptual evolution.

Table 5 Pre- and post-intervention answers to the question, "What makes the Moon change its appearance from day to day?"

Participant Pre-intervention Post-intervention

\begin{tabular}{|c|c|c|}
\hline Adam & (No answer) & The Sun \\
\hline Benoît & Part of the Moon is often hidden by fog. & $\begin{array}{l}\text { It's because part of the Moon is lit by the Sun, } \\
\text { and when it turns around the Earth, the bright } \\
\text { part changes place. }\end{array}$ \\
\hline Bernard & $\begin{array}{l}\text { I think it's the way light strikes the Moon and } \\
\text { the position of the Moon. }\end{array}$ & It's the way the Moon reflects light from the Sun. \\
\hline Louis & Maybe the way the Sun is positioned at sunset. & $\begin{array}{l}\text { It's the position of the Moon that changes } \\
\text { everything. It's also because of the position of } \\
\text { the Earth. }\end{array}$ \\
\hline Maude & $\begin{array}{l}\text { I believe it's because the Moon turns around } \\
\text { itself and Earth, thus, because it changes } \\
\text { position, its appearance changes. }\end{array}$ & $\begin{array}{l}\text { It turns around the Earth and changes position } \\
\text { with respect to the Sun, so from the Earth, } \\
\text { depending on its position, we see different } \\
\text { shapes. }\end{array}$ \\
\hline Nadine & $\begin{array}{l}\text { I don't remember really, but it has to do } \\
\text { with Sun and shadow. }\end{array}$ & $\begin{array}{l}\text { It's because the Moon doesn't always show us its } \\
\text { bright side. Depending on its position and the } \\
\text { position of the Earth, a shadow is created. }\end{array}$ \\
\hline
\end{tabular}


Verbal Description by Participants: After the planetarium session, we asked participants to individually describe the sequence as well as the mechanism of the lunar phases in their own words, as if they were describing it to their parents (this replaced the activity of sorting the pictures of the Moon). Bernard and Benoit were first to describe the sequence of the lunar phases, in the right order and using the correct nomenclature. When asked to describe the mechanism of the lunar phases, Benoit answered, "Well, the Sun shines on the Moon, and since the Moon turns [revolves] around Earth, the bright part we see changes, well, [the Moon] changes, with its different parts." When we measure the evolution of Benoit's conception of the lunar phases (from fog to "filling up" to the rotation of the Moon), we see saw that it became much closer to the scientific model than it was at the beginning of the intervention. When asked to describe the mechanism of the lunar phases, Bernard said it was hard for him to find the words to describe what he visualized (hence perhaps his short written answers to the questionnaire). The researcher suggested he use a flashlight and a ball to describe his mental model. With these objects, Bernard had no difficulty explaining that the lunar phases are produced by the revolution of the Moon, lit up by the Sun, around Earth. Interestingly, for his demonstration, Bernard chose an allocentric point of view on the SEM by moving the ball in a circular orbit in front of the flashlight and pointing at the center of the orbit to mark the position of Earth. We see that as a clear sign of the effect that the allocentric point of view shown during the digital planetarium session had on the evolution of his understanding of the lunar phases.

It was not difficult for Maude to describe the mechanism of the Moon's phases either: "What we see is the light from the Sun that the Moon reflects. Since the Moon moves and Earth moves, and everything is in orbit, we see different phases. If everything stayed fixed, we would only see the same phase all the time. But because everything moves, we see phases, the Moon growing larger until it is full, and then getting thinner. That's what causes the phases of the Moon."

Like Bernard, Nadine used the ball and flashlight to explain the lunar phases, and her point of view was allocentric as well. Apart from the fact that she used a clockwise revolution (as seen from above Earth's North Pole), and presented the phases in reverse order, her description of the mechanism of the lunar phases was scientifically correct.

It is interesting to note that both girls in the group had a clear understanding of the mechanism of the lunar phases after instruction, even better than Louis and Adam (see below). Conversely, Linn and Petersen (1985) have documented the fact that girls commonly have more difficulty with spatial reasoning than boys of the same age. This is not what we found in our research, although with very limited power to generalize. It may be that the allocentric perspective provided by the digital full-dome planetarium experience helped the two girls build an accurate three-dimensional mental model of the SEM, as suggested by previous research in planetarium education (Bishop 1980; Plummer 2009).

When asked for their descriptions of the mechanism of the lunar phases, Louis and Adam were unable to come up with a valid explanation. Their answers echoed what was revealed by their written answers, namely that their conceptions did not reflect the scientific model. However, there seemed to be some conceptual evolution on the part of Louis, who was at least able to describe verbally the correct sequence of the phases, but not Adam.

Summary: In the written and verbal descriptions of the mechanism of the lunar phases, we saw signs of conceptual evolution toward the scientific model in four out of six participants, a result that we attribute in part to the allocentric perspective on the SEM provided by the digital fulldome planetarium. This is particularly clear in the case of Bernard and Nadine, who both demonstrated the mechanism of the lunar phases using a concrete model that reproduced the allocentric perspective that participants were exposed to under the planetarium dome. 
Participants' Transfer of the Lunar Phase Model

Phases of Mercury: After flying to a point in space where we could see the orbits of Earth and Venus, we observed Venus revolve around the Sun, and participants were asked to guess what the phase of Venus was as seen from Earth at different positions along its orbit (see Fig. 4). With the experience gained by watching the Moon previously, participants had no difficulty answering correctly, applying the lunar phase model to Venus. Bernard went even further by stating that it must also be the case for the planet Mercury, a point that was duly demonstrated by bringing up Mercury and its orbit on the dome, and watching it revolve around the Sun. This spontaneous transfer of the lunar phase model to another, similar situation, shows how well the scientific perspective was integrated into Bernard's mental model.

Phases of Earth: We landed our virtual spacecraft on the near side of the Moon to watch the phases of Earth (see Fig. 5). That Earth could show phases like the Moon, Venus, or Mercury came as a complete surprise to participants. But once we set the Moon in motion along its orbit and watched the phase of Earth change, not only were participants able to explain why we saw the phases of Earth, they were also able to deduce what phase of the Moon were visible at the same moment for an observer on Earth, realizing that the phases of Earth and the Moon were reversed, i.e., full earth happens at new moon and vice versa, and Earth's first quarter is seen when the Moon is at last quarter, etc. In fact, it was Benoît, whose conceptions evolved almost constantly throughout the entire session, who first came to this realization, quickly followed by Bernard and the other participants.

Post-test Discussion: Finally, back in the meeting room for the post-test discussion, Bernard suggested that it would be nice to visit Jupiter and its satellites to watch their phases as seen from the giant planet. This is another example of transfer of the lunar phase model to a different situation (after Mercury and Earth) that proves how much Bernard was now able to use his scientifically correct mental model of the phases and apply it to new situations.

Summary: Observing the phases of Venus as seen from Earth and the phases of Earth as seen from the Moon gave participants the opportunity to apply their new mental models of the lunar phases to similar situations. Not only were they able to correctly predict the aspect of the phases in these new situations, but they were even able to go one step further by applying the phase model to new situations, such as Mercury and Jupiter's satellites, and shift mentally between the Moon and Earth to predict the phase of the Moon based on the phase of Earth as seen from the Moon at the same moment. This is a clear indication that participants gained a certain mental flexibility in shifting perspectives and the ability to apply their newly developed model of the lunar phases to new situations.

\section{Conclusion and Future Research}

Now that we have presented and analyzed the results of the first implementation of our educational scenario to teach the lunar phases to children aged 12 to 14 years old in an 
allocentric digital full-dome planetarium, we provide the following answers to the research questions that were the main focus of the present work.

What Conceptions About the Lunar Phases Did Participants Hold Before Experiencing the Educational Intervention in the Allocentric Digital Full-Dome Planetarium to Teach the Phases of the Moon? As expected, the pre-test answers to the questionnaire and interviews that probed participants' explanations of the lunar phases revealed several different misconceptions, including the most prevalent misconception that the phases are caused by something (such as fog) hiding the Moon, as well as the misconception that the rotation of the Moon on itself causes phases, and the misconception that the phases are linked to the position of the setting Sun. But we also encountered a new misconception, Benoît's "filling-up" model, based on the assumption that the Moon grows from new to full, as if it were a jar being filled up or an orange whose pieces were being put back together until they formed a round fruit. We think this misconception might be based on vocabulary, and that the expression "full moon" (pleine Lune in French) evokes a Moon that is filled up or complete. However, in the absence of other research that finds this misconception among other learners, it might simply be idiosyncratic and limited to this particular individual.

How Did Participants' Conceptions About the Lunar Phases Evolve During and Immediately After Experiencing the Educational Intervention in the Allocentric Digital Full-Dome Planetarium? We clearly saw conceptions change and evolve during and after the planetarium intervention. For instance, Benoît went from believing that fog was hiding the Moon to believing that the Moon was filling up. Then, during the dome session, he tried to explain the phases using the rotation of the Moon on its axis. In the post-test, he finally came up with a description that was very close to the scientific model. The conceptions of the lunar phases held by Bernard, Maude, and Nadine also evolved toward the scientific model to such a degree that Bernard was able to spontaneously apply his mental model to new situations, such as Mercury and the satellites of Jupiter, and Benoît was able to mentally shift from the Moon's surface to Earth to correctly guess the phase of the Moon as seen from an observer on Earth. Based on how Bernard and Nadine used a ball and a flashlight to demonstrate the mechanism of the lunar phases from an allocentric point of view on the SEM during the post-test discussion, we feel confident that the allocentric perspective on the Moon provided by the digital planetarium played a large part in the evolution of their conceptions. We also witnessed conceptual change in Louis's explanation of the lunar phases, however it still fell short of the scientific model. As for Adam, his minimal participation in the discussions and short written answers did not allow us to conclude anything other than the fact that conceptual change did not occur for him. Should we be disappointed by the fact that all participants did not embrace the scientific model after instruction in the digital planetarium? Probably not. Mulholland and Ginns (2008) remind us that "[...] the most difficult concepts to change [are] those requiring students to use three dimensional mental models in their reasoning and thinking about the Sun, Earth, Moon system in terms of their relative configurations in space" (p. 395). According to Sadler (1998), "progress toward scientific understanding of key scientific concepts [...] is not simple or straightforward. Students do not move quickly from no opinion to the scientific understanding, but they do change." Participants spent only $90 \mathrm{~min}$ under the dome, which is a very short time to teach such a difficult concept as the lunar phases, and there was no follow-up study to evaluate medium- and long-term 
retention. It is indeed quite possible that participants' conceptions had not yet stabilized after the intervention and have continued to evolve, or have even reverted back to previous misconceptions (Strike \& Posner 1985). But we feel confident that the allocentric planetarium session created strong mental images that will stay with participants; however, this idea will need to be tested within a longer-term study.

What Aspects of the Educational Intervention in the Allocentric Digital Full-Dome Planetarium Did Participants Appreciate the Most? What Aspects Did They Appreciate the Least? Based on their reactions after entering the dome, during the planetarium session discussions, and during the post-test discussion, participants were clearly motivated by the experience and appreciated being in a digital planetarium, watching realistic simulations of astronomical phenomena from different perspectives. Overall, participants said they loved the quality of the simulation and the fact that they were out in space looking at the Moon up close. Bernard recalled that during his previous visits to the Planétarium de Montréal, a traditional, opto-mechanical planetarium, only the geocentric point of view was shown. But he found it much more interesting to see things from different perspectives, or "to see in other dimensions," as he put it. This motivational aspect of the digital planetarium echoes Roussou (2006), who remarked that "[...] what most studies [on the educational value of virtual-reality technology] were able to consistently confirm was the high level of learner enjoyment, especially when compared to other media" (p. 58). Benoît summed up his overall experience by saying, "It was magical, really magical!" When asked about the length of the planetarium intervention and the pre- and post-intervention sessions, participants complained that it might have been too long, an aspect that will have to be looked at closely in future implementations. Participants were clearly tired at the end of the 3-h session, which included the pre- and post-tests, the planetarium intervention, and the post-test discussion.

How Can the Educational Intervention in the Allocentric Digital Full-Dome Planetarium be Improved, Based on the Results of its First Implementation? There are many ways in which we think our educational intervention in the allocentric digital full-dome planetarium can be improved to help participants build a better mental model of the SEM and change their misconceptions toward the scientific model. We hinted at some of them in the previous sections, and more are presented below. From the particular vantage point in space that was presented throughout the allocentric portion of the planetarium intervention, the Moon constantly looked like a first quarter moon (bright side to the right) as it revolved around Earth. This made it relatively easy for participants to reconcile the geocentric and allocentric perspectives on the first quarter, full, and new moon phases, as they simply had to mentally translate their position in a straight line from our virtual spacecraft to Earth, and then look at the Moon straight up (first quarter), or rotate over 90 degrees to the left (full moon) or to the right (new moon). But reconciling the last quarter moon proved much more difficult, as they had to translate to Earth and rotate over 180 degrees to "look back" at the Moon (see Fig. 2).

The same difficulty arose when we moved to a polar view of the Moon's orbit and participants were asked to guess the geocentric aspect of the Moon at several positions along its orbit, as seen by a telescope on Earth (see Fig. 3). Using pictures of different lunar phases as a guide, participants easily predicted the aspect of the waxing phases (including crescent and gibbous moons), as well as the full and new moon, but had more difficulty predicting the aspect of the waning phases, especially 
the last quarter moon. The instructor suggested that they stand up and look at the scene by leaning their heads down, as if looking at the scene upside down, and that helped. In retrospect, however, it would have been more useful to move back and forth in space with our virtual spacecraft from a point outside the Moon's orbit to a point hovering just above Earth's North Pole, thus constantly switching from an allocentric to a geocentric perspective on the Moon. This might have helped participants develop more agility in shifting perspectives mentally.

Also, there seemed to be some confusion among participants between the mechanism of the lunar phases and the Moon's rotation, an aspect that was not addressed during the planetarium session. A simulation of the Moon's rotation as seen from a polar perspective, coupled with a clear demonstration of the revolution of our satellite over 1 month, might help dispel the notion that there is a link between the two phenomena.

Following a suggestion by Bernard, time could be spent flying toward Jupiter to watch the phases of its four major satellites from a point located just above the giant planet's North Pole. Indeed, this would be a direct application of the lunar phase model to a similar situation, even more so than watching the phases of Venus from Earth.

The concept of the "self-shadow" (Young \& Guy 2008), i.e., the fact that the Moon casts a shadow on itself, which explains why half the Moon is always dark, could also be demonstrated. This would provide participants with some experience of shadows cast by spherical objects onto themselves, something they are not typically familiar with (Parker \& Heywood 1998; Stahly et al. 1999). That might also help participants understand the change of shape of the terminator as the lunar phases evolve. All of these suggestions will have to be tested during a future implementation of our educational scenario.

Measuring angles between the Sun and Moon, while drawing the phase every day on their moon calendar, might help participants put more focus on the apparent diurnal motion of the Moon as it moves away from the Sun during the waxing phases, and closer to it during the waning phases, and link this information to the sequence of the lunar phases. Recognizing, naming, and drawing the gibbous phases on their moon calendar proved more difficult for participants than the other phases, a result that confirms previous findings by Bell and Trundle (2008), and might require some kind of special instruction as to how to sketch these particular phases more accurately. Leaving blank spaces on the moon calendar for participants to note the name of the phases might also help them build the proper vocabulary. Lastly, the planetarium intervention could provide even more scaffolding to participants by using visual aids to demonstrate, for instance, that the Sun is the only source of light in the solar system.

One aspect of our intervention that we think is particularly important is the presence of a live, knowledgeable instructor under the dome, who is in constant dialogue with participants while guiding their discovery of the simulation. We do not think we could have achieved the same results if we had not been able to answer questions and provide information to learners exactly when they needed it, according to the evolution of their own conceptions during the educational intervention. For instance, it was very important to dispel the notion that the Moon had reverted back to new moon right after full moon, as Benoît had thought after watching the full moon dip below the horizon, or to be able to show the phases of Mercury as Bernard had suggested. There was an element of improvised actions and comments as the 
educational scenario unfolded that could not have been prepared beforehand. The adaptability of the human agent is of paramount importance if any educational simulation is to be successful, especially in an environment as foreign to everyday, common experience as a digital full-dome planetarium that takes the audience into outer space.

\section{Future Research}

Now that we have outlined numerous improvements that we can bring to our intervention, the next step is to implement them and test a second iteration of our educational intervention. This should be done in the near future, but it will involve more than simply repeating the work we have presented here. The scenario will need to be adapted so that the intervention can be presented under a larger dome, with more participants, using participatory methods adapted to larger groups (Gould 2001). The type of evaluation that we have used so far, which is exclusively qualitative, will also give way to a more quantitative type of assessment, as we will want to measure the effectiveness of our educational intervention against other popular teaching methods, such as a month-long Moon observation campaign followed by modeling the SEM with balls and a flashlight (Kavanagh et al. 2005). Our questionnaire will have to evolve as well to become a true quantitative instrument, such as the Lunar Phases Concept Inventory (Lindell \& Olsen 2002).

One significant question that remains concerns the importance of allocentrism versus immersion in a digital full-dome planetarium. Does one aspect dominate the other? If so, which? Yu et al. (in press) hinted at the importance of both aspects in explaining their results, but could not isolate one from the other. One study comparing two educational interventions under the same immersive planetarium dome, one with a strong allocentric component, could help distinguish the effects of the two characteristics. Another important question is the effect of providing an allocentric perspective on astronomical systems on the evolution of boys and girls' mental models, and the possibility that this new approach helps girls overcome an apparent difficulty in developing their spatial abilities (Linn \& Petersen 1985).

Lastly, it would be interesting to apply what we have learned so far about the educational impact of presenting an allocentric perspective on astronomical phenomena in a digital full-dome planetarium to other astronomical topics that exhibit strong three-dimensional characteristics, such as the diurnal and annual motions of Earth, the seasons, eclipses, the annual motions of the planets, light curves of binary stars, and the shape of the Milky Way. The digital planetarium, which immerses the audience in a realistic simulation of the universe and allows the presentation of multiple points of view on astronomical phenomena, geocentric as well as allocentric, provides new ways of teaching astronomy that we could only dream of a few years ago. Now that this tool is becoming more and more accessible, even in a portable format that can go from one school to another, a whole new research program in astronomy education is unfolding. The sky is (no longer) the limit.

Acknowledgments The author wishes to thank Pr. Marcel Thouin, our thesis advisor, as well as Pr. Jesus Vazquez-Abad, Pr. Louise Poirier, and Pr. Patrice Potvin for enlightening discussions. Mr. Pierre Lacombe, Director of the Planétarium Rio Tinto Alcan in Montréal, was instrumental in the completion of this work. The author also wishes to thank reviewers of the first draft of this manuscript for extremely useful comments and suggestions. 


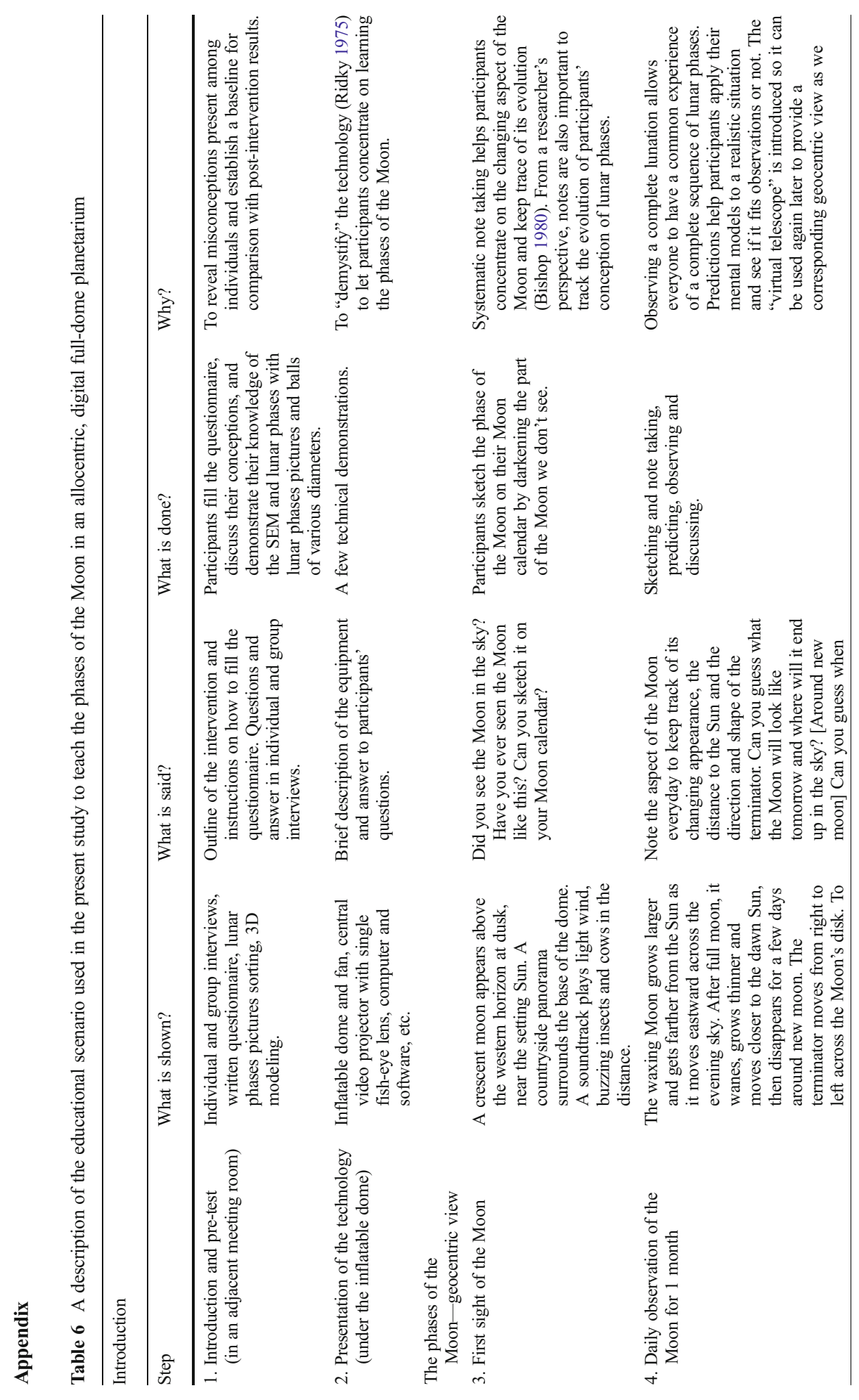




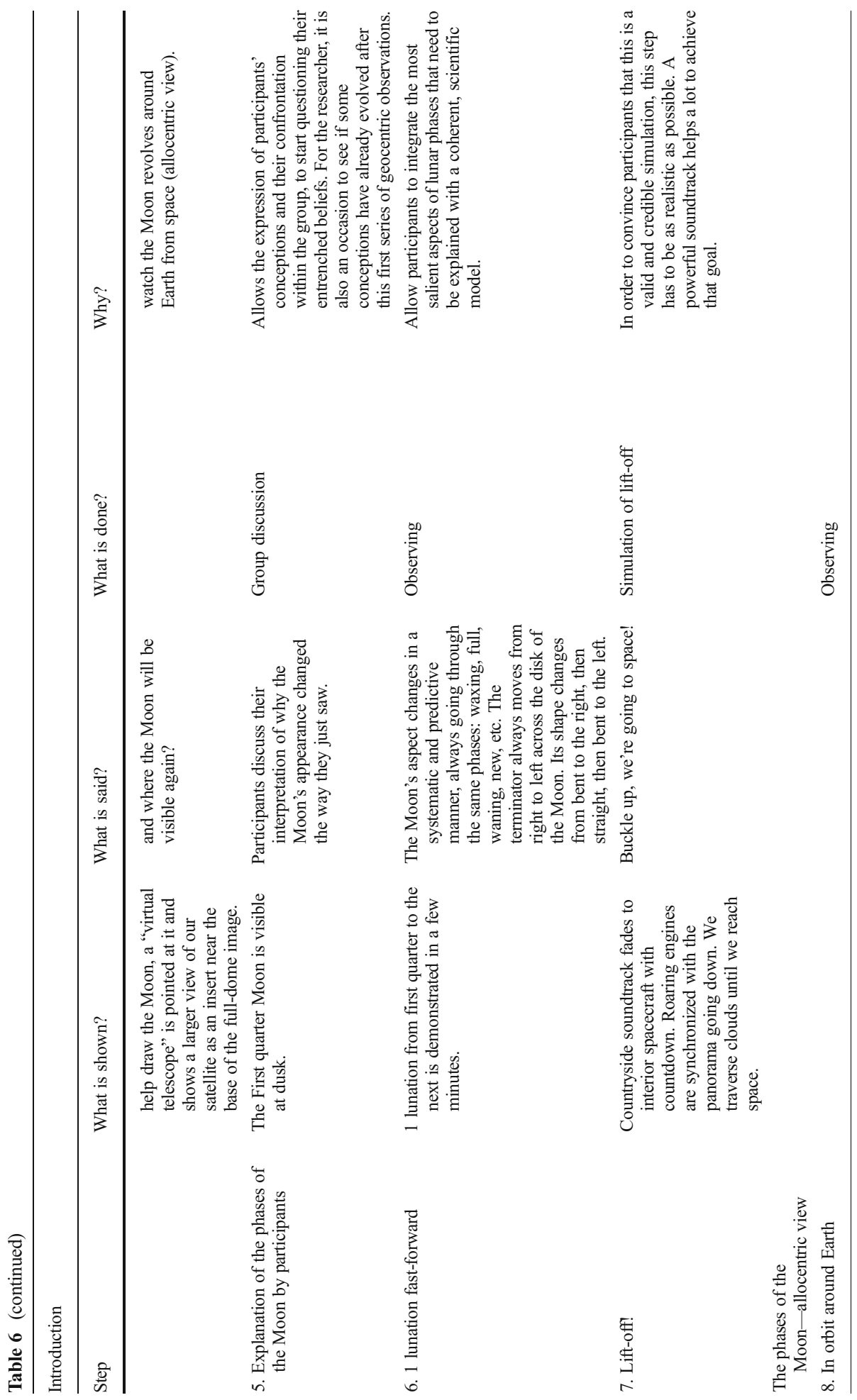




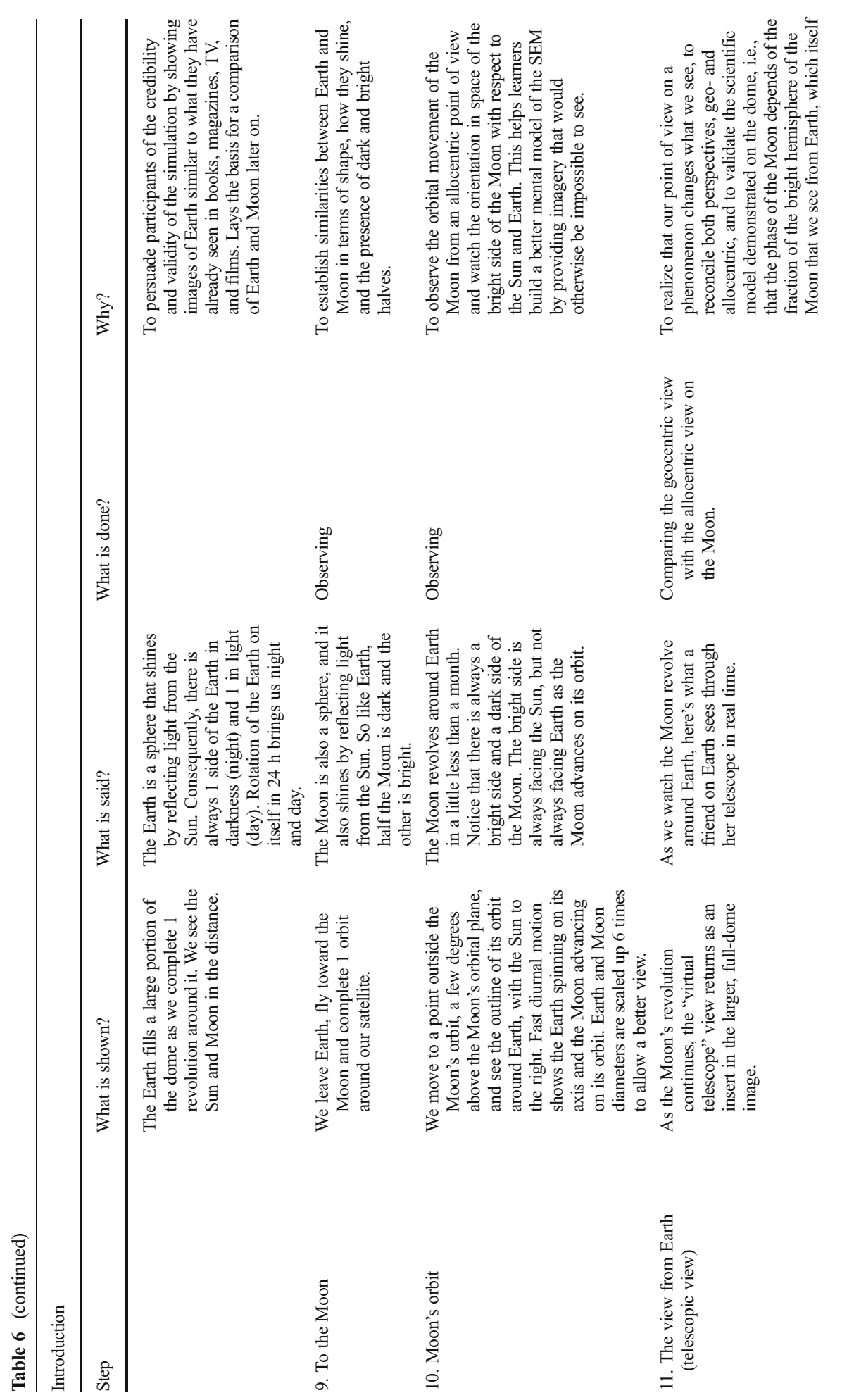




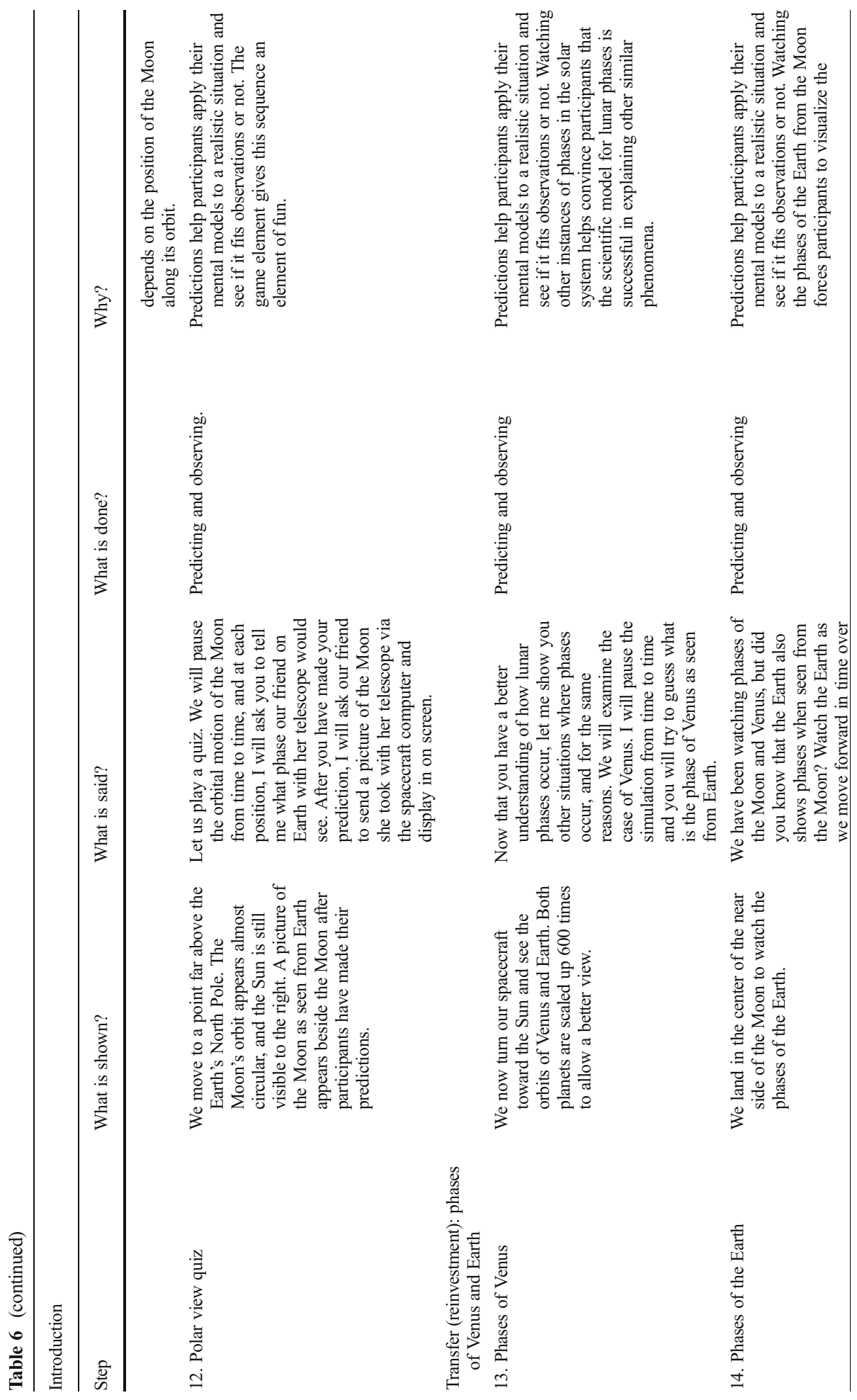




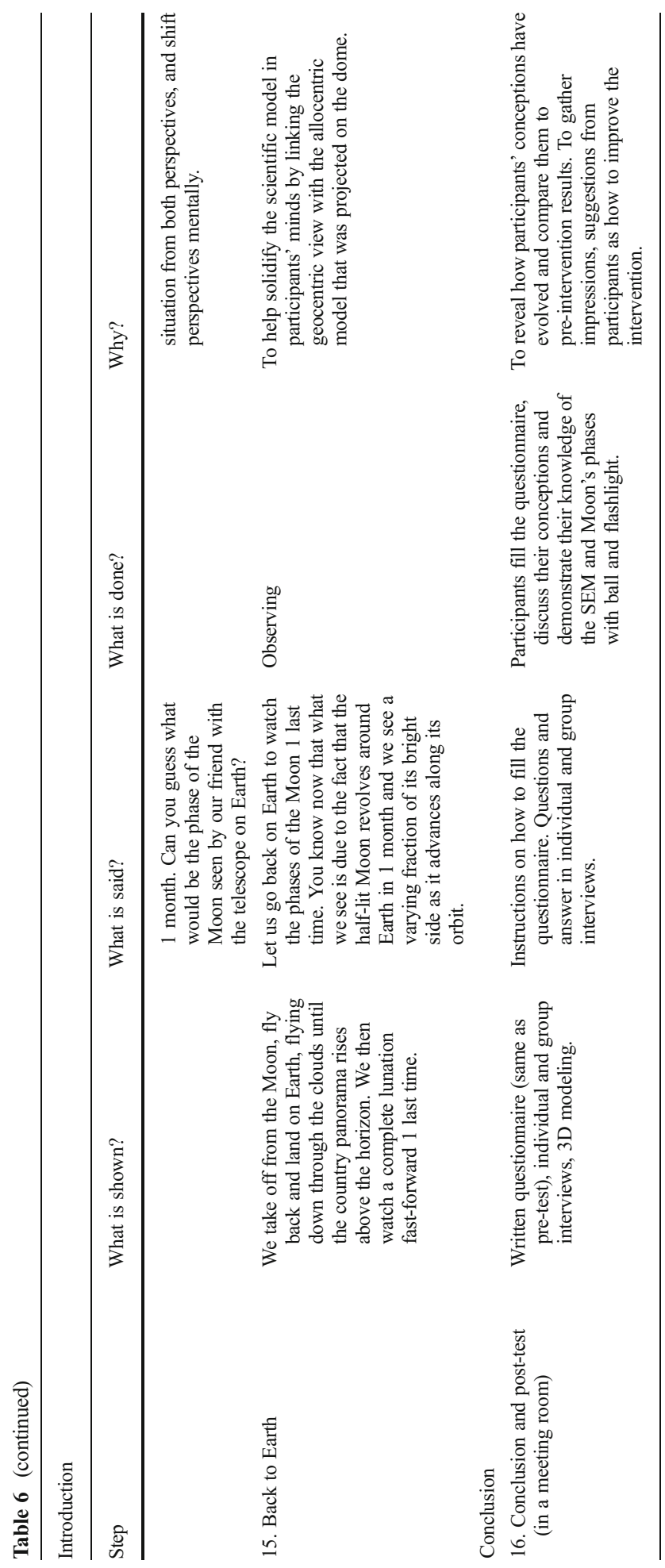


Open Access This article is distributed under the terms of the Creative Commons Attribution License which permits any use, distribution, and reproduction in any medium, provided the original author(s) and the source are credited.

\section{References}

Abbott, B., Emmart, C., \& Wyatt, R. (2004). Virtual universe. Natural History, 113(3).

Artigue, M. (1996). Ingénierie didactique. In J. Brun (Ed.), Didactique des mathématiques (pp. 243-274). Paris: Delachaux \& Niestlé.

Bakas, C., \& Mikropoulos, T. A. (2003). Design of virtual environments for the comprehension of planetary phenomena based on students' ideas. International Journal of Science Education, 25(8), 949-967.

Barnett, M., \& Morran, J. (2002). Addressing children's alternative frameworks of the moon's phases and eclipses. International Journal of Science Education, 24(8), 859-879.

Barnett, M., Yamagata-Lynch, L., Keating, T., Barab, S. A., \& Hay, K. E. (2005). Using virtual reality computer models to support student understanding of astronomical concepts. Journal of Computers in Mathematics and Science Teaching, 24(4), 333-356.

Baxter, J. H. (1989). Children's understanding of familiar astronomical Events. International Journal of Science Education, 11, 502-513.

Bell, R. L., \& Trundle, K. C. (2008). The use of a computer simulation to promote scientific conceptions of moon phases. Journal of Research in Science Teaching, 45(3), 346-372.

Bishop, J. E. (1980). The development and testing of a participatory planetarium unit emphasizing projective astronomy concepts and utilizing the karplus learning cycle, student model manipulation, and student drawing with eight-grade students. Unpublished $\mathrm{PhD}$ thesis, University of Akron, Akron, OH.

Bishop, J. E. (2002). Astronomy Concepts Appropriate for Different Ages. Paper presented at the 16th International Planetarium Society Conference, Wichita, KS, July 28-August 1, 2002.

Black, A. A. (2005). Spatial ability and earth science conceptual understanding. Journal of Geoscience Education, 53(4), 402-414.

Brazell, B. D., \& Espinoza, S. (2009). Meta-analysis of planetarium efficacy research. Astronomy education review, 8(1), doi:10.3847/AER2009033.

Brewer, W. F. (2008). Naïve theories of observational astronomy: Review, analysis, and theoretical implications. In S. Vosniadou (Ed.), International handbook of research on conceptual change. New York: Routledge.

Chartrand, M. R. I. (1973). A fifty year anniversary of a two thousand year dream: the history of the planetarium. The Planetarian, 2(3), 95-101.

Chastenay, P. (2007). Enseigner les sciences au planétarium. In P. Potvin, M. Riopel, \& S. Masson (Eds.), Regards multiples sur l'enseignement des sciences (pp. 135-151). Québec: MultiMondes.

Chastenay, P. (2013). Conception et évaluation d'une intervention didactique à propos des phases de la Lune dans un planétarium numérique. Unpublished PhD Thesis, Université de Montréal, Montréal, Canada.

Cobb, P., Confrey, J., diSessa, A., Lehrer, R., \& Schauble, L. (2003). Design experiments in educational research. Educational Researcher, 32(1), 9-13.

Comins, N. F. (n.d.). Heavenly Errors. Online: http://www.physics.umaine.edu/ncomins/moons.htm. Accessed October 3, 2013.

Design-Based Research Collective. (2003). Design-based research: an emerging paradigm for educational inquiry. Educational Researcher, 32(1), 5-8.

Driver, R. (1981). Pupils' alternative frameworks in science. European Journal of Science Education, 3(1), 93101.

Dunlop, J. (2000). How children observe the universe. Publication of the Astronomical Society of Australia, 17, $194-206$.

Faidit, J.-M. (2009). Planetariums in the World. IAU Symposium 260. The Role of Astronomy in Society and Culture. doi:10.1017/S1743921311003292.

Gazit, E., Yair, Y., \& Chen, D. (2005). Emerging conceptual understanding of complex astronomical phenomena by using a virtual solar system. Journal of Science Education and Technology, 14(5-6), 459-470.

Gazit, E., Yair, Y., \& Chen, D. (2006). The gain and pain in taking the pilot seat: learning dynamics in a non immersive virtual solar system. Virtual Reality, 10(3-4), 271-282. doi:10.1007/s10055-006-0053-3.

Gorard, S., Roberts, K., \& Taylor, C. (2004). What kind of creature is a design experiment? British Educational Research Journal, 30(4), 577-590.

Gould, A. (2001). Activities for big audience. Paper presented at the 15th International Planetarium Society Conference, Montréal, Canada, July 10-13, 2000. 
Kavanagh, C., Agan, L., \& Sneider, C. (2005). Learning about phases of the Moon and eclipses: A guide for teachers and curriculum developers. Astronomy Education Review, 4(1), doi:10.3847/AER2005002.

Keating, T., Barnett, M., Barab, S. A., \& Hay, K. E. (2002). The virtual solar system project: developing conceptual understanding of astronomical concepts through building three-dimensional computational models. Journal of Science Education and Technology, 11(3), 261-275.

Lantz, E. (2002). The digital planetarium. Paper presented at the 16th International Planetarium Society Conference, Wichita, KS, July 28-August 1, 2002.

Lantz, E. (2007). A survey of large-scale immersive displays. Paper presented at the Emerging Display Technology Conference, San Diego, CA, August, 2007.

Li, J., Jarvis, C. H., \& Brunsdon, C. (2010). The use of immersive real-time 3D computer graphics for visualisation of dilution of precision in virtual environments. International Journal of Geographical Information Science, 24(4), 591-605. doi:10.1080/13658810902989995.

Limniou, M., Roberts, D., \& Papadopoulos, N. (2008). Full immersive virtual environment CAVE in chemistry education. Computers \& Education, 51(2), 584-593. doi:10.1016/j.compedu.2007.06.014.

Lin, J. J.-W., Duh, H. B. L., Parker, D. E., Abi-Rached, H., \& Furness, T. A. (2002). Effects of field of view on presence, enjoyment, memory, and simulator sickness in a virtual environment. Paper presented at the IEEE Virtual Reality Conference, Orlando, FL, March 24-28, 2002.

Lindell, R. S., \& Olsen, J. P. (2002). Developing the lunar phases concept inventory. In S. Franklin, K. Cummings, \& J. Marx (Eds.), Proceedings of the 2002 physics education research conference. New York: PERC Publishing.

Linn, M. C., \& Petersen, A. C. (1985). Emergence and characterization of sex differences in spatial ability: a meta-analysis. Child Development, 56(6), 1479-1498.

Liu, S.-C. (2005). Models of "the heavens and the earth": an investigation of German and Taiwanese students' alternative conceptions of the universe. International Journal of Science and Mathematics Education, 3(2), 295-325.

LoPresto, M. C., \& Murrell, S. R. (2011). An astronomical misconceptions survey. Journal of College Science Teaching, 40(5), 14-22.

Lowry, W. H. (1984). A consideration of visual pattern perception readiness as related to constellation study. The Planetarian, 13(3), 34-37.

McLellan, H. (1996). Virtual realities. In D. H. Jonassen (Ed.), Handbook of research for educational communications and technology (pp. 457-487). New York: Simon \& Schuster Macmillan.

Miller, B. W., \& Brewer, W. F. (2010). Misconceptions of astronomical distances. International Journal of Science Education, 32(12), 1549-1560.

Moore, C. J., \& Huber, R. (2001). Internet tools for facilitating inquiry. Contemporary Issues in Technology and Teacher Education, 1(4), 451-464.

Mulholland, J., \& Ginns, I. (2008). College MOON project Australia: preservice teachers learning about the moon's phases. Research in Science Education, 38(3), 385-399.

National Research Council. (2002). Scientific research in education. Washington, DC: National Academy Press.

Nussbaum, J. (1985). The earth as a cosmic body. In R. Driver, E. Guesne, \& A. Tiberghien (Eds.), Children's ideas in science (pp. 170-192). Milton Keynes: Open University Press.

Ohlsson, S., Moher, T., \& Johnson, A. (2000). Deep Learning in Virtual Reality: How to Teach Children that the Earth is Round. Proceedings of the 22nd Annual Conference of the Cognitive Science Society, Philadelphia, PA, August 13-15, 2000.

Parker, J., \& Heywood, D. (1998). The earth and beyond: developing primary teachers' understanding of basic astronomical events. International Journal of Science Education, 20(5), 503-520. doi:10.1080/ 0950069980200501.

Petersen, M. C. (2013). The 2012 state of the dome address. Paper presented at the IMERSA Summit, Denver, CO, July 10, 2013

Philips, W. C. (1991). Earth Science Misconceptions. The Science Teacher (February), 21-23.

Pitluga, L. (1968). An experimental comparison of planetarium teaching programs. Unpublished Master Thesis, State University College at Oswego, Oswego, NY.

Plummer, J. D. (2009). Early elementary students' development of astronomy concepts in the planetarium. Journal of Research in Science Teaching, 46(2), 192-209. doi:10.1002/tea.20280.

Posner, G. J., Strike, K. A., Hewson, P. W., \& Gertzog, W. A. (1982). Accommodation of a scientific conception: toward a theory of conceptual change. Science Education, 66(2), 211-227.

Prothero, J. D., \& Hoffman, H. G. (1995). Widening the field-of-view increases the sense of presence in immersive virtual environments. Human interface technology laboratory (HITL) technical report TR-95-2. Seattle: University of Washington.

Psotka, J. (1995). Immersive training systems: virtual reality and education and training. Instructional Science, 23(5-6), 405-431. 
Ridky, R. W. (1975). The mystique effect of the planetarium. School Science and Mathematics, 75(6), 505-508.

Rieber, L. P. (2004). Microworlds. In D. H. Jonassen (Ed.), Handbook of research on educational communications and technology (2nd ed., pp. 583-603). Mahwah: Laurence Erlbaum Associates.

Roald, I., \& Mikalsen, O. (2001). Configuration and dynamics of the earth-sun-moon system: an investigation into conceptions of deaf and hearing pupils. International Journal of Science Education, 23(4), 423-440.

Roussou, M. (2006). Interactivity and learning: examining primary school children's activity within virtual environments. Unpublished PhD Thesis, University of London, London, UK.

Ruiz, L., \& Acker, A. (2006). Les systèmes de projection des planétariums : de l'optomécanique au numérique. La lettre de l'OCIM, 108 (novembre-décembre), 14-19.

Rusk, J. (2003). Do science demonstration in the planetarium enhance learning? Planetarian, 32(1), 5-8.

Sadler, P. M. (1992). The initial knowledge state of high school astronomy students. Unpublished PhD Thesis, Harvard University, Boston, MA.

Sadler, P. M. (1998). Psychometric models of student conceptions in science: reconciling qualitative studies and distractor-driven assessment instruments. Journal of Research in Science Teaching, 35(3), 265-296.

Schoon, K. J. (1992). Students' alternative conceptions of earth and space. Journal of Geological Education, 40, 209-214.

Sharp, J. G. (1995). Children's astronomy: implications for curriculum developments at key stage 1 and the future of infant science in England and Wales. International Journal of Early Years Education, 3(3), 17-49.

Sharp, J. G. (1996). Children's astronomical beliefs: a preliminary study of year 6 children in South-West England. International Journal of Science Education, 18(6), 685-712.

Sharp, J. G., Bowker, R., Mooney, C. M., Grace, M., \& Jeans, R. (1999). Teaching and learning astronomy in primary schools. School Science Review, 80(292), 75-86.

Shavelson, R. J., Phillips, D. C., Towne, L., \& Feuer, M. J. (2003). On the science of education design studies. Educational Researcher, 32(1), 25-28.

Stahly, L. L., Krockover, G. H., \& Shepardson, D. P. (1999). Third grade students' ideas about the lunar phases. Journal of Research in Science Teaching, 36(2), 159-177.

Strike, K. A., \& Posner, G. J. (1985). A conceptual change view of learning and understanding. In L. H. T. West \& A. L. Pines (Eds.), Cognitive structures and conceptual change (pp. 211-231). Orlando: Academic.

Sumners, C., Reiff, P., \& Weber, W. (2008). Learning in an immersive digital theater. Advances in Space Research, 42(11), 1848-1854. doi:10.1016/j.asr.2008.06.018.

Sun, K.-T., Lin, C.-L., \& Wang, S.-M. (2009). A 3-D virtual reality model of the sun and the moon for E-learning at elementary schools. International Journal of Science and Mathematics Education, 8, 689-710.

Tan, D. S., Gergle, D., Scupelli, P. G., \& Pausch, R. (2003). With similar visual angles, larger displays improve spatial performance. Paper presented at the Conference on Human Factors in Computing Systems, Fort Lauderdale, FL, April 5-10, 2003.

Tan, D. S., Gergle, D., Scupelli, P. G., \& Pausch, R. (2004). Physically large displays improve path integration in $3 \mathrm{~d}$ virtual navigation tasks. Paper presented at the Conference on Human Factors in Computing Systems, Vienna, Austria, April 24-29, 2004.

Taylor, I., Barker, M., \& Jones, A. (2003). Promoting mental model building in astronomy education. International Journal of Science Education, 25(10), 1205-1225.

Thouin, M. (1997). La didactique des sciences de la nature au primaire. Sainte-Foy: MultiMondes.

Thouin, M. (2004). Enseigner les sciences et la technologie au préscolaire et au primaire. Québec: MultiMondes.

Tomlinson, G. (1997). Grade appropriate concepts. Planetarian, 26(1), 7-10.

Treagust, D. F. (1988). Development and use of diagnostic tests to evaluate students misconceptions in science. International Journal of Science Education, 10(2), 159-169.

Trundle, K. C., Atwood, R. K., \& Christopher, J. E. (2006). Preservice elementary teachers' knowledge of observable moon phases and pattern of change in phases. Journal of Science Teacher Education, 17(2), 87-101.

Trundle, K. C., \& Bell, R. L. (2003). Using planetarium software to teach standards-based lunar concepts. School Science and Mathematics, 103(8), 397-401.

Trundle, K. C., \& Bell, R. L. (2010). The use of a computer simulation to promote conceptual change: a quasiexperimental study. Computers \& Education, 54(4), 1078-1088.

Trundle, K. C., \& Troland, T. H. (2005). The Moon in children's literature. Science and Children, 43(2), 40-43.

Trundle, K. C., Troland, T. H., \& Pritchard, T. G. (2008). Representations of the Moon in children's literature: an analysis of written and visual text. Journal of Elementary Science Education, 20(1), 17-28.

Van der Maren, J.-M. (1996). Méthodes de recherche pour l'éducation (2e édition). Montréal: Presses de l'Université de Montréal.

Vosniadou, S., \& Brewer, W. F. (1994). Mental models of the day/night cycle. Cognitive Science, 18, $123-183$. 
Windschitl, M., Winn, W., \& Headley, N. (2001). Using immersive visualizations to promote the understanding of complex natural systems: learning inside virtual puget sound. Paper presented at the Annual Meeting of the National Association for Research on Science Teaching, St. Louis, MO, March 25-28, 2001.

Winn, W. D. (1993). A conceptual basis for educational applications of virtual reality. Human interface technology laboratory (hitl) technical report TR-93-9. Seattle: University of Washington.

Winn, W. D. (2002). Current trends in educational technology research: the study of learning environments. Educational Psychology Review, 14(3), 331-351.

Yair, Y., Mintz, R., \& Litvak, S. (2001). 3D-virtual reality in science education: an implication for astronomy teaching. Journal of Computers in Mathematics and Science Teaching, 20(3), 293-305.

Young, T., \& Guy, M. (2008). The Moon's phases and the self shadow. Science and Children, 46(1), 30-35.

Youngblut, C. (1998). Educational uses of virtual reality technology. Institute for defense analyses document D-2128. Alexandria: IDA.

Yu, K. C. (2005). Digital full-domes: the future of virtual astronomy education. Planetarian, 34(3), 6-11.

Yu, K. C., \& Sahami, K. (2007). Visuospatial Astronomy Education in Immersive Digital Planetariums. Communicating Astronomy with the Public, 242-245.

Yu, K. C., Sahami, K., \& Denn, G. (2010). Student ideas about Kepler's laws and planetary orbital motions. Astronomy Education Review, 9(1), doi:10.3847/AER2009069.

Yu, K. C., Sahami, K., Sahami, V. A., \& Sessions, L. (in press). Using a digital planetarium for teaching seasons to undergraduates.

Zimmerman, L., Spillane, S., Reiff, P., \& Sumners, C. (2014). Comparison of student learning about space in immersive and computer environments. Journal and Review of Astronomy Education and Outreach, 1(1), A5-A20. 